Grant-in-Aid for Scientific Research (S)

Real Estate Markets, Financial Crisis, and Economic Growth

: An Integrated Economic Approach

Working Paper Series No.19

\title{
Asset Bubbles and Bailouts
}

\author{
Tomohiro Hirano \\ Masaru Inaba \\ Noriyuki Yanagawa
}

May, 2015

HIT-REFINED PROJ ECT

Institute of Economic Research, Hitotsubashi University

Naka 2-1, Kunitachi-city, Tokyo 186-8603, J APAN

Tel: +81-42-580-9145

E-mail: hit-tdb-sec @ier.hit-u.ac.jp

http://www.ier.hit-u.ac.jp/ifn/ 


\title{
Asset Bubbles and Bailouts*
}

\section{Tomohiro Hirano $^{\dagger} \quad$ Masaru Inaba ${ }^{\ddagger} \quad$ Noriyuki Yanagawa ${ }^{\S}$}

\author{
First Version, April 2011
}

This Version, March 2015

\begin{abstract}
This paper investigates the relationship between bubbles and governmentbailouts. As long as bubble size is relatively small, bubbles increase production level, but once the size becomes too large, then bubbles reduce it. Given this non-monotonic relationship, we show that bailouts for bursting bubbles may positively influence ex-ante production efficiency and relax the existence condition of stochastic bubbles. The level of bailouts has a non-monotonic relationship with production efficiency and a "partial bailout" policy achieves production efficiency. Moreover, it examines the welfare effects of bailout policies rigorously and shows that even non-risky bubbles may be undesirable for taxpayers.
\end{abstract}

Keywords: Bubble Size, Anticipated Bailouts, Production Efficiency, Boom-Bust Cycles, Optimal Bailout Policy

${ }^{*}$ This is a revised version of our previous working paper, Hirano, Tomohiro and Noriyuki Yanagawa. (2012 January, CIRJE Working Paper) "Asset Bubbles and Bailout", and Hirano, Inaba, and Yanagawa (2013 April, CARF Working Paper). We have benefited greatly from discussions with Harald Uhlig, Nobuhiro Kiyotaki, Jean Tirole, Kiminori Matsuyama, Ricardo Reis, Joseph Stiglitz, Jianjun Miao, Katsuhito Iwai, Kalin Nikolov(discussant), and Valentin Haddad(discussant). We also thank Pietro Reichlin, Albert Martin, Jaume Ventura, Fumio Hayashi, Boyan Jovanovic, and seminar participants at 2014 JME-SNB-SCG Conference, 2012 AFR Summer Institute of Economics and Finance, 2012 CIGS Conference on Macroeconomic Theory and Policy, New York Fed, Philadelphia Fed, Bank of Canada, Columbia University, University of Kent, University of Southampton, University of Florida. A part of this work was financially supported by JSPS KAKENHI Grant Number 25220502.

${ }^{\dagger}$ Corresponding Author (The University of Tokyo) : tomohih@gmail.com

${ }^{\ddagger}$ Kansai University/The Canon Institute for Global Studies

$\S$ The University of Tokyo 
JEL classification: E32, E44, E61 


\section{Introduction}

2 Many countries have experienced bubble-like dynamics, notably the United States before and 3 after the Great Depression and Japan in the 1990s. The bursting of asset bubbles is generally

4 followed by significant contractions in real economic activity. To mitigate these contractions, government tend to provide various types of bailouts, such as the purchase of legacy assets at inflated prices or the proposal of capital injection policy. Although such bailout initiatives are becoming more frequent, the effects of these policies have thus far been under-examined in the theoretical literature, especially in full-blown macroeconomic models. For example, although bailouts may mitigate the adverse ex-post effects of the bubble bursting, it remains unclear what happens if bailouts are anticipated ex-ante. Do they change the emergence conditions of bubbles? Do they affect boom-bust? More generally, to what extent are expost bailouts efficient from an ex-ante perspective? Further, can we derive an optimal bailout

policy? In this paper, we theoretically investigate these questions using a simple infinitehorizon general equilibrium model with financial imperfection and stochastic bubbles.

In contrast to the previous literature, we show that bailouts may positively influence ex-ante production efficiency. Much of the recent theoretical literature on bailout policies investigates the moral hazard consequences of bailouts (e.g., Diamond and Rajan, 2012; Farhi and Tirole, 2009, 2012a) and finds that moral hazard negatively affects ex-ante efficiency. This paper, however, shows that the effects of bailouts provided after the collapse of bubbles have the opposite effect. An intuitive reason for this finding comes from the crowd-in effect of bubbles. If the financial market is imperfect, bubbles may be able to crowd in investments because the bubbles have a positive wealth effect and relax borrowing constraints. In contrast, ex-post bailouts make bubbles safer and more profitable assets, and demand for bubbles subsequently rises. This higher demand raises the price of bubbles and increases the crowd-in effect. Hence, bailouts positively influence ex-ante production efficiency. To explain this point clearly, we extend the approach taken by Kiyotaki (1998) by developing a macroeconomic model with heterogeneous investments and financial market imperfection.

Anticipated bailouts induce low-productivity entrepreneurs to buy risky bubble assets. 
By encouraging such risk-taking behavior, anticipated bailouts also affect the existing conditions of asset bubbles. We show that bubbles that have a high probability of bursting do not occur in the absence of government guarantees. In other words, if bailouts are guaranteed by the government, riskier bubbles can arise.

The second contribution of this paper is that it examines the possibility of partial bailouts. In reality, the provision of bailouts is not comprehensive. For example, in the recent global financial crisis, AIG was rescued, while Lehman Brothers was not. In this paper, we consider this possibility. A financial safety net is provided by the government following the collapse of bubbles. We focus on a bailout in which the government guarantees bubble investments against losses resulting from the collapse of bubbles. The aim of bailouts is to recapitalize the net worth of entrepreneurs and mitigate economic contractions. An important assumption in our model is that not all entrepreneurs who suffer losses from bubble investments are necessarily rescued; that is, some entrepreneurs are rescued while others are not. The government can choose the percentage of entrepreneurs rescued. This assumption captures the possibility of partial bailouts, and we show that partial bailouts are superior. To achieve ex-ante production efficiency, partial bailouts are more desirable than full bailouts. This point comes from the crowd-out effect of bubbles. Although bubbles have a crowd-in effect, it is well known in the literature on bubbles (for example, Tirole (1985)) that they also have a crowd-out effect on investments.

One notable point of this paper is that bubble size has non-monotonic effects on ex-ante production efficiency (that is, the production level up to the point at which the bubble bursts) from the crowd-in and crowd-out effects. From this result, we can derive that even bailouts have non-monotonic impacts on ex-ante production efficiency when bailout policies are anticipated. We show that expansions in government guarantees initially crowds in productive investments, thereby increasing production efficiency. Too generous guarantees, however, lead to strong crowd-out effects, thereby decreasing ex-ante production efficiency. This non-monotonic impact on ex-ante production efficiency suggests that there is a certain bailout level at which ex-ante production efficiency is maximized. Under the bailout policy, 
the output level in each period is increased by improving production efficiency. This implies, however, that the economy experiences a sharp drop in output when bubbles collapse. In other words, such a bailout policy may increase boom-bust and require large amounts of public funds following the collapse of bubbles. This finding suggests a trade-off between economic stability and efficient resource allocation, which leads to our third contribution.

The third contribution of this paper is that we rigorously derive the effects of bailouts on economic welfare, including transitional dynamics. In our model, given an initial state variable (i.e., capital stock), the economy cannot jump to the stationary state immediately. Thus, in computing welfare under different bailout levels, we need to take into account welfare effects, including the transitional paths. Since there are heterogeneous agents in this economy, it is difficult to examine total welfare directly. Instead, we examine the welfare of each type of agent. For welfare analyses, the non-monotonic impact on production efficiency is important. Given the fact that the wage rate is positively correlated with production efficiency, the welfare of workers has a non-monotonic relation with the broader provision of bailouts. We show that partial bailouts are optimal for taxpayers - that is, having no bailouts and having overly generous bailouts are not optimal for taxpayers. Moreover, workers may have to pay tax to rescue bubble holders. Then, in cases of riskier bubbles, the optimal bailout level for taxpayers is lower than the level at which production efficiency is maximized, which has an important implication for boom-bust. To maximize taxpayers' welfare, the government must sacrifice some production efficiency in order to reduce the size of bubbles and soften boom-bust. In contrast, an entrepreneur's welfare monotonically increases with broader bailout provisions because entrepreneurs receive a higher transfer from an expansion in government guarantees and enjoy the wealth effect of consumption. Moreover, government guarantees provide an insurance device for entrepreneurs when they face idiosyncratic productivity shocks, thus enhancing the consumption-smoothing effect and their welfare. Thus, there are differences between taxpayers and rescued entrepreneurs concerning the desirable bailout level.

Finally, we discuss the welfare effects of bailout policies that make stochastic bubbles 
non-stochastic (e.g., government debt as a bailout tool). It is widely believed that nonstochastic bubbles are better for welfare than stochastic bubbles. Thus, if the government could make stochastic bubbles non-stochastic, it would be beneficial. However, we show that stochastic bubbles can be better than non-stochastic bubbles from the perspective of taxpayers' welfare, which suggests that increasing the fragility of bubbles might actually enhance the welfare of taxpayers.

\subsection{Related Literature}

Recent studies of rational bubbles have provided a theoretical framework for analyzing the macroeconomic effects of asset bubbles. In particular, seminal works such as Farhi and Tirole (2012b), Martin and Ventura, (2012), and Woodford (1990) have enriched the argument about the consequences of asset bubbles by showing that they may have a crowd-in effect. ${ }^{1}$ Martin and Ventura (2012) explored the mechanism of the crowd-in effect by using an overlapping generations model in which none of the future cash flow is pledgeable to investors. With zero pledgeability, it is impossible to transfer the resources of potential lenders to entrepreneurs, and an under-investment situation occurs. They showed that if entrepreneurs with productive investments can create bubbles, they can sell those bubbles and increase investments. Farhi and Tirole (2012b) considered a three-period overlapping generations model with limited corporate sector pledgeability and outside liquidity. In their model, the existence of bubbles raises the interest rate and shifts resources from the outside liquidity to the corporate sector; that is, bubbles crowd investment in.

This paper is closely related to these pioneer papers in terms of the crowd-in effect, although it uses an infinite-horizon general equilibrium model with limited pledgeability. ${ }^{2}$ Given two types of investments (high tech and low tech), bubbles shift resources from lowtech investments to high-tech investments, and thus they crowd investment in totally. More

\footnotetext{
${ }^{1}$ In addition to these papers, a growing body of literature has recently examined asset bubbles and macro dynamics (e.g., Aoki and Nikolov, 2011; Caballero and Krishnamurthy, 2006; Kocherlalota, 2009; Hellwing and Lorenozni, 2009; Hirano and Yanagawa, 2010; Miao and Wang, 2011).

${ }^{2}$ Woodford (1990) also examined an infinite-horizon model, but it assumed zero pledgeability.
} 
${ }^{3}$ Another potential benefit would be that infinite horizon models would be more suitable for realistic quantitative explorations that the recent macroeconomic literature emphasize. Developing an infinite horizon model with bubbles would be beneficial for quantitative analyses.

${ }^{4}$ In this vein, Uhlig (2010) models a systemic bank run in light of the recent financial crisis. His analysis supports the argument that the outright purchase of troubled assets by the government at above current market prices can both alleviate financial crises as well as provide taxpayers with returns greater than those for safe securities. Similarly, Diamond and Rajan (2012) and Farhi and Tirole (2009, 2012a) examine the moral hazard consequences of bailouts and welfare analysis to derive optimal regulations and bailout policies. These papers, however, do not address bubbles. Our paper lends support to Uhlig's (2010) results in its development of a rigorous welfare analysis and builds on the findings of the other three papers by proposing optimal bailout policies following the collapse of bubbles. Moreover, rather than using a three-period model with an endowment economy, we examine the effects of bailouts in a full-blown dynamic macroeconomic 
model with a production economy.

Among the previous works that have used dynamic macroeconomic models, Brunnermeier and Sannikov (2011), Gertler and Kiyotaki (2010), and Kiyotaki and Moore (2008) examine government bailouts (i.e., credit market interventions) in a liquidity crisis, while Gertler and Karadi (2011) and Roch and Uhlig (2012) adopt dynamic macroeconomic models to analyze the welfare effects of bailouts. Roch and Uhlig (2012), for example, provide a theoretical framework to analyze the dynamics of a sovereign debt crisis and bailouts. Their paper, which is based on an endowment economy, characterizes the minimal actuarially fair bailouts that restore the good equilibrium. In contrast, our model is based on a production economy. Hence, the anticipated bailouts affect welfare greatly through the change in production. Gertler and Karadi (2011) analyze whether the government's interventions in a crisis (i.e., direct lending by the central banks) can improve post-crisis welfare. In contrast, our paper takes into account the anticipated effects of government policy and computes welfare from an ex-ante perspective. 


\section{The Model}

\subsection{Framework}

$$
E_{0}\left[\sum_{t=0}^{\infty} \beta^{t} \log c_{t}^{i}\right]
$$


entrepreneurs with H-projects "H-types" and the entrepreneurs with L-projects "L-types".

We assume that because of frictions in a financial market, the entrepreneur can pledge at most a fraction $\theta$ of the future return from his/her investment to creditors as in Kiyotaki and Moore (1997). In such a situation, in order for debt contracts to be credible, debt repayment cannot exceed the pledgeable value. That is, the borrowing constraint becomes:

$$
r_{t} b_{t}^{i} \leq \theta q_{t+1} \alpha_{t}^{i} z_{t}^{i}
$$

where $q_{t+1}$ is the relative price of capital to consumption goods at date $t+1{ }^{6} r_{t}$ and $b_{t}^{i}$ are the gross interest rate and the amount of borrowing at date $t$. The parameter $\theta \in(0,1]$, which is assumed to be exogenous, can be naturally taken to be the degree of imperfection of the financial market.

In this economy, there are bubble assets denoted by $x$. The aggregate supply of bubble assets is assumed to be constant over time $X$. As in Tirole (1985), we define bubble assets as those assets that do not generate any payoff or dividend. However, under some conditions, the prices of bubble assets become positive, which means that bubbles arise in equilibrium. Here, following Weil (1987), we consider stochastic bubbles, in the sense that they may collapse. In each period, bubble prices become zero (i.e., bubbles burst) at a probability of $1-\pi$ conditional on survival in the previous period. A lower $\pi$ means riskier bubbles, because the bursting probability is higher. In line with the literature in this regard, once bubbles collapse, they do not arise again unless agents change their expectations about bubbles' formation through, for example, unexpected shocks. This implies that bubbles persist with a probability $\pi(<1)$ and that their prices are positive until they switch to being equal to zero. Let $P_{t}^{x}$ be the per unit price of bubble assets at date $t$ in terms of consumption goods. $P_{t}^{x}=P_{t}>0$ if bubbles survive at date $t$ with probability $\pi$, and $P_{t}^{x}=0$ if they collapse at date $t$ with probaility $1-\pi$. As we will show, $P_{t}$ is endogenously determined in equilibrium and is affected by expectations about government bailouts.

\footnotetext{
${ }^{6}$ On an equilibrium path, $q_{t+1}$ is not affected by the collapse of bubbles. Hence, there is no uncertainty with regard to $q_{t+1}$.
} 


$$
c_{t}^{i}+z_{t}^{i}+P_{t}^{x} x_{t}^{i}=q_{t} \alpha_{t-1}^{i} z_{t-1}^{i}-r_{t-1} b_{t-1}^{i}+b_{t}^{i}+P_{t}^{x} x_{t-1}^{i}+m_{t}^{i} .
$$

where $x_{t}^{i}$ be the level of bubble assets purchased by a type $i$ entrepreneur at date $t$. The left hand side of (4) is expenditure on consumption, investment, and the purchase of bubble assets. The right hand side is the available funds at date $t$, which is the return from investment in the previous period minus debts repayment, plus new borrowing, the return from selling bubble assets, and bailout transfer, $m_{t}^{i}$. We define the net worth of the entrepreneur at date $t$ as $e_{t}^{i} \equiv q_{t} \alpha_{t-1}^{i} z_{t-1}^{i}-r_{t-1} b_{t-1}^{i}+P_{t}^{x} x_{t-1}^{i}+m_{t}^{i}$.

When bubbles collapse at the beginning of date $t$, all the wealth invested in bubble assets is wiped out. This decreased wealth and the resulting net worth of entrepreneurs lead to severe contractions during the bursting of bubbles. Although the government bails out entrepreneurs to mitigate these contractions, not all entrepreneurs are necessarily rescued. To formulate the possibility of so-called "partial bailouts", we assume that only a certain proportion $\lambda \in[0,1]$ of the entrepreneurs who suffer losses from bubble investments are rescued. $\lambda=0$ means that no-entrepreneurs are rescued, while $\lambda=1$ means that all are rescued. A rise in $\lambda$ means expansions in the government's financial safety net. This bailout scheme suggests that from an ex-ante perspective, each entrepreneur anticipates government bailouts with a probability $\lambda$. When entrepreneur $i$ is rescued, we assume that the government guarantees bubble investments against losses and that the bailout is proportional to the entrepreneur's holdings of bubble assets:

$$
m_{t}^{i}=\tilde{d}_{t}^{i} x_{t-1}^{i}
$$

Here, we specifically consider a bailout policy that fully guarantees bubble investments against losses. Hence, $\tilde{d}_{t}^{i}=d_{t}=P_{t}>0$ if the agent $i$ is rescued when bubbles collapse at date $t$. Otherwise $m_{t}^{i}=\tilde{d}_{t}^{i}=0$. This bailout policy fully guarantees the rate of return on bubble assets, but only a certain proportion of entrepreneurs is rescued. The main reason 


\footnotetext{
${ }^{7}$ Kocherlakota (1992) shows that the short sale constraint plays an important role for the emergence of asset bubbles in an endowment economy with infinitely lived agents.

${ }^{8}$ Even if we consider workers with $N$ measure, all the results in our paper hold.
} 


$$
c_{t}^{u}=w_{t}-T_{t}^{u} .
$$

$2 c_{t}^{u}$ is the equilibrium consumption level of a worker at date $t$, and $T_{t}^{u}$ is a tax level at date

$3 t$. When bubbles collapse, government levies a lump sum tax on workers and transfers those

4 funds to entrepreneurs who suffer losses from bubble investments. This means that workers 5 are taxpayers and incur the direct costs of bubbles' collapsing. Thus, $T_{t}^{u}>0$ only when 6 bubbles collapse, while $T_{t}^{u}=0$ if they survive. As in Farhi and Tirole (2012a), the aim of this transfer policy (i.e., bailout policy) is to boost the net worth of entrepreneurs. In our model, this increased net worth can mitigate the adverse effects of the collapse of bubbles. In

$$
q_{t}=\sigma K_{t}^{\sigma-1} \text { and } w_{t}=(1-\sigma) K_{t}^{\sigma} \text {, }
$$

where $K_{t}$ is the aggregate capital stock at date $t$.

\footnotetext{
${ }^{9}$ Let us mention the main reason behind the transfer policy from workers to entrepreneurs. In our model, as long as the government transfers resources among entrepreneurs, the aggregate wealth of entrepreneurs does not increase. As a result, economic contractions following the collapse of bubbles are not mitigated. The transfer policy from workers to entrepreneurs, however, increases the aggregate wealth of entrepreneurs and mitigates such contractions. We explain this point more in depth in the the Appendix C.
} 


\subsection{Equilibrium}

Let us denote the aggregate consumption of $\mathrm{H}$-and L-types and workers at date $t$ as $\sum_{i \in H_{t}} c_{t}^{i} \equiv$ $C_{t}^{H}, \sum_{i \in L_{t}} c_{t}^{i} \equiv C_{t}^{L}, C_{t}^{u}$, where $H_{t}$ and $L_{t}$ mean a family of H-and L-types at date $t$. Similarly, let $\sum_{i \in H_{t}} z_{t}^{i} \equiv Z_{t}^{H}, \sum_{i \in L_{t}} z_{t}^{i} \equiv Z_{t}^{L}, \sum y_{t} \equiv Y_{t}, \sum_{i \in H_{t}} b_{t}^{i} \equiv B_{t}^{H}, \sum_{i \in L_{t}} b_{t}^{i} \equiv B_{t}^{L}, \sum b_{t}^{u} \equiv B_{t}^{u}$, $\sum n_{t} \equiv N_{t}, \sum_{i \in H_{t} \cup L_{t}} x_{t}^{i}+\sum x_{t}^{u} \equiv X_{t}$ be the aggregate investments of each type, the aggregate output, the aggregate borrowing of each type, the aggregate labor input, and the aggregate demand for bubble assets. Then, the market clearing condition for goods, credit, capital, labor, and bubble assets are

$$
\begin{aligned}
C_{t}^{H}+C_{t}^{L}+C_{t}^{u}+Z_{t}^{H}+Z_{t}^{L} & =Y_{t}, \\
B_{t}^{H}+B_{t}^{L}+B_{t}^{u} & =0, \\
K_{t} & =\sum_{i \in H_{t} \cup L_{t}} k_{t}^{i}, \\
N_{t} & =1, \\
X_{t} & =X .
\end{aligned}
$$

2 The competitive equilibrium is defined as a set of prices $\left\{r_{t}, w_{t}, q_{t}, P_{t}^{x}\right\}_{t=0}^{\infty}$ and quantities $\left\{C_{t}^{H}, C_{t}^{L}, C_{t}^{u}, B_{t}^{H}, B_{t}^{L}, B_{t}^{u}, N_{t}, Z_{t}^{H}, Z_{t}^{L}, X_{t}, K_{t+1}, Y_{t}\right\}_{t=0}^{\infty}$, such that (i) the market clear4 ing conditions, (10)-(14), are satisfied in each period, and (ii) each entrepreneur chooses consumption, borrowing, investment, and the amount of bubble assets, $\left\{c_{t}^{i}, b_{t}^{i}, z_{t}^{i}, x_{t}^{i}\right\}_{t=0}^{\infty}$, to maximize his/her expected discounted utility (1) under the constraints (2)-(6), taking into consideration the bursting probability of bubbles and the bailout probability, and (iii) Each worker's behavior is given by (7).

\subsection{Optimal Behaviour of Entrepreneurs}

We now characterize the equilibrium behavior of entrepreneurs. We focus on the equilibrium where

$$
q_{t+1} \alpha^{L} \leq r_{t}<q_{t+1} \alpha^{H}
$$


In equilibrium, interest rate must be at least as high as $q_{t+1} \alpha^{L}$, since nobody lends to the projects if $r_{t}<q_{t+1} \alpha^{L}$. Moreover, if the interest rate is higher than the rate of return of H-projects, nobody borrows. Hence, this assumption is not restrictive at all ${ }^{10}$.

Since the utility function is log-linear, each entrepreneur consumes a fraction $1-\beta$ of the net worth in each period, that is, $c_{t}^{i}=(1-\beta) e_{t}^{i}$. For H-types at date $t$, the borrowing constraint (3) is binding since $r_{t}<q_{t+1} \alpha^{H}$ and the investment in bubbles is not attractive, that is, (6) is also binding. We will verify this result in the Technical Appendix O. Then, by using (3), (4), and (6), the investment function of H-types at date $t$ can be written as

$$
z_{t}^{i}=\frac{\beta\left(q_{t} \alpha_{t-1}^{i} z_{t-1}^{i}-r_{t-1} b_{t-1}^{i}+P_{t}^{x} x_{t-1}^{i}+m_{t}^{i}\right)}{1-\frac{\theta q_{t+1} \alpha^{H}}{r_{t}}} .
$$

This is a popular investment function under financial constraint problems ${ }^{11}$, except for the fact that the presence of bubble assets and bailout transfer affect the net worth. We see that the investment equals the leverage, $1 /\left[1-\left(\theta q_{t+1} \alpha^{H} / r_{t}\right)\right]$, times a fraction $\beta$ of the net worth. From this investment function, we understand that for the entrepreneurs who purchased bubble assets in the previous period, they are able to sell those assets to Ltypes at the time they encounter H-projects. If their net worth increases by selling bubbles, the increase of net worth boosts their investments. Moreover, the expansion level of the investment is more than the direct increase of the net worth because of the leverage effect. In our model, the entrepreneurs buy bubble assets for speculation when they have L-projects, and sell those assets when they have opportunities to invest in H-projects.

\footnotetext{
${ }^{10}$ When $r_{t}=q_{t+1} \alpha^{H}$, bubbles cannot exist. This is because, for stochastic bubbles to arise when entrepreneurs are risk-averse, the expected rate of return on bubbles, $\pi P_{t+1} / P_{t}$, must be strictly greater than the safe interest rate, $r_{t}$, that is, $\pi P_{t+1} / P_{t}>r_{t}$ must hold. If the expected return on bubbles is sufficiently high and is sufficiently greater than the rate of return on high-productivity investments, H-types may buy bubbles. In those cases, $P_{t+1} / P_{t}>q_{t+1} \alpha^{H}$, that is, bubbles' growth rate is strictly greater than the rate of return on high-productivity investments, which is the highest return on real assets. In this case, bubbles grow faster than the economy's growth rate, and the economy cannot support growing bubbles. At some point in the future, the size of the bubbles, $\phi_{t}$, exceeds $1, \phi_{t} \geq 1$, which is an explosive path and cannot be an equilibrium path. Hence, in equilibria with bubbles, bubbles are absorbed by L-type entrepreneurs.

${ }^{11}$ See, for example, Bernanke and Gertler (1989), Bernanke et al. (1999), Holmstrom and Tirole (1998), Kiyotaki and Moore (1997), and Matsuyama (2007).
} 


$$
z_{t}^{i}+P_{t}^{x} x_{t}^{i}+\left(-b_{t}^{i}\right)=\beta e_{t}^{i}
$$

Each L-type allocates his/her savings, $\beta e_{t}^{i}$, into three assets, i.e., $z_{t}^{i}, P_{t}^{x} x_{t}^{i}$, and $\left(-b_{t}^{i}\right)$. Each 2 L-type chooses optimal amounts of $b_{t}^{i}, x_{t}^{i}$, and $z_{t}^{i}$ so that the marginal expected utility from investing in three assets is equalized. By solving the utility maximization problem explained in the Technical Appendix L, we can derive the demand function for bubble assets of an L-type:

$$
P_{t} x_{t}^{i}=\frac{\delta(\lambda) \frac{P_{t+1}}{P_{t}}-r_{t}}{\frac{P_{t+1}}{P_{t}}-r_{t}} \beta e_{t}^{i},
$$

where $\delta(\lambda) \equiv \pi+(1-\pi) \lambda$. From (17), we learn that an entrepreneurs's portfolio decision depends on its perceptions of risk, which in turn depends on both the bursting probability

of bubbles $(1-\pi)$ and expectations about government bailouts $(\lambda)$. A rise in $\lambda$ encourages L-type's risk-taking to buy more bubble assets.

The remaining fraction of savings is split across $z_{t}^{i}$ and $\left(-b_{t}^{i}\right)$ :

$$
z_{t}^{i}+\left(-b_{t}^{i}\right)=\frac{[1-\delta(\lambda)] \frac{P_{t+1}}{P_{t}}}{\frac{P_{t+1}}{P_{t}}-r_{t}} \beta e_{t}^{i}
$$

Since investing in L-projects $\left(z_{t}^{i}\right)$ and secured lending to other entrepreneurs $\left(-b_{t}^{i}\right)$ are both safe assets, $z_{t}^{i} \geq 0$ if $r_{t}=q_{t+1} \alpha^{L}$, and $z_{t}^{i}=0$ if $r_{t}>q_{t+1} \alpha^{L}$. Moreover, when $r_{t}=q_{t+1} \alpha^{L}$, investing in L-projects and secured lending to other entrepreneurs are indifferent for L-types, aggregate investment level of L-types, $Z_{t}^{L}$, is determined from (10).

\subsection{Dynamics}

We are now in a position to derive the dynamics of the bubble economy. Since we assume that rational bubbles are stochastic, that is, bubbles persist with probability $\pi(<1)$, here, we focus on the dynamics until bubbles collapse, i.e., $P_{t}^{x}=P_{t}>0$. 


$$
Z_{t}^{H}+Z_{t}^{L}+P_{t} X=\beta A_{t}
$$

1 we have the evolution of aggregate capital stock:

$$
K_{t+1}=\left\{\begin{array}{cl}
\alpha^{H} \frac{\beta p A_{t}}{1-\frac{\theta \alpha^{H}}{\alpha^{L}}}+\alpha^{L}\left(\beta A_{t}-\frac{\beta p A_{t}}{1-\frac{\theta \alpha^{H}}{\alpha^{L}}}-P_{t} X\right) & \text { if } r_{t}=q_{t+1} \alpha^{L} \\
\alpha^{H}\left[\beta A_{t}-P_{t} X\right] & \text { if } r_{t}>q_{t+1} \alpha^{L} .
\end{array}\right.
$$

where $A_{t} \equiv q_{t} K_{t}+P_{t} X$ is the aggregate wealth of entrepreneurs at date $t$ in the bubble economy, and $\sum_{i \in H_{t}} e_{t}^{i}=p A_{t}$ is the aggregate wealth of H-types at date $t$. (More details about aggregation of each variable will be explained in the Technical Appendix M). When $r_{t}=q_{t+1} \alpha^{L}$, both types of entrepreneurs may invest. The first term and the second term of the first line represent the capital stock at date $t+1$ produced by H-and L-types, respectively. When $r_{t}>q_{t+1} \alpha^{L}$, only H-types invest. From (18), we know $Z_{t}^{H}=\beta A_{t}-P_{t} X$. $\left(-P_{t} X\right)$ in (19) captures a traditional crowd-out effect of bubbles analyzed in Tirole (1985), i.e., the presence of bubble assets crowds savings away from investments. On the other hand, the first line can be rearranged as

$$
\left(\alpha^{H}-\alpha^{L}\right) \frac{\beta p A_{t}}{1-\frac{\theta \alpha^{H}}{\alpha^{L}}}+\alpha^{L}\left(\beta A_{t}-P_{t} X\right),
$$

and the first term, $\left(\alpha^{H}-\alpha^{L}\right) \frac{\beta p A_{t}}{1-\frac{\theta \alpha}{\alpha^{L}}}$, is an increasing function of $A_{t}$; that is, it is an increasing function of $P_{t} X$. This is the source of the crowd-in effect of bubbles. In this model, the crowd-in effect comes from the positive wealth effect of the H-type entrepreneurs. The wealth effect reallocates the funds toward H-investments from L-investments. In order to make these crowd-in and crowd-out effects more clearly, we check the determination process of the interest rate. 
As long as $r_{t}>q_{t+1} \alpha^{L}$, the interest rate is determined by the credit market clearing condition (11), which can be written as

$$
\frac{\beta p A_{t}}{1-\frac{\theta q_{t+1} \alpha^{H}}{r_{t}}}+P_{t} X=\beta A_{t} .
$$

That is, the aggregate savings of entrepreneurs, $\beta A_{t}$, flow to aggregate $\mathrm{H}$-investments and bubbles. By defining $\phi_{t} \equiv P_{t} X / \beta A_{t}$ as the size of bubbles (the share of the value of bubbles), we can rewrite the above relation as

$$
r_{t}=\frac{q_{t+1} \theta \alpha^{H}\left(1-\phi_{t}\right)}{1-p-\phi_{t}}
$$

8 It follows that $r_{t}$ increases with $\phi_{t}$, reflecting the tightness of the credit markets.

1 Thus, the equilibrium interest rate is determined as

$$
r_{t}=q_{t+1} \operatorname{Max}\left[\alpha^{L}, \frac{\theta \alpha^{H}\left(1-\phi_{t}\right)}{1-p-\phi_{t}}\right]
$$

2 In other words, $r_{t}=q_{t+1} \alpha^{L}$ and $Z_{t}^{L} \geq 0$ if $\phi_{t} \leq \phi^{*} \equiv \frac{\alpha^{L}(1-p)-\theta \alpha^{H}}{\alpha^{L}-\theta \alpha^{H}}$, and $r_{t}>q_{t+1} \alpha^{L}$ and $Z_{t}^{L}=0$ if $\phi_{t}>\phi^{*}$.

$4 \quad$ Hence, by using $\phi_{t}$, (19) can be written as

$$
K_{t+1}=\left\{\begin{array}{cc}
\frac{\left[\left(1+\frac{\alpha^{H}-\alpha^{L}}{\alpha^{L}-\theta \alpha^{H}} p\right) \beta \alpha^{L}-\alpha^{L} \beta \phi_{t}\right]}{1-\beta \phi_{t}} \sigma K_{t}^{\sigma} & \text { if } \phi_{t} \leq \phi^{*}, \\
\frac{\alpha^{H} \beta\left[1-\phi_{t}\right]}{1-\beta \phi_{t}} \sigma K_{t}^{\sigma} & \text { if } \phi_{t}>\phi^{*} .
\end{array}\right.
$$

5 The dynamical system of this economy is mainly characterized by this (21). As described 6 in Figure 1, as long as bubbles can exist (We explain the existence condition of bubbles 7 in Proposition 2 of section 4 later), the dynamics of $K_{t+1} / K_{t}^{\sigma}=K_{t+1} / Y_{t}$ is an increasing 8 function of $\phi_{t}$ as long as $\phi_{t}<\phi^{*}$ and it becomes a decreasing function of $\phi_{t}$ if $\phi_{t}>\phi^{*}$. In other 
words, $\phi^{*} \equiv \frac{\alpha^{L}(1-p)-\theta \alpha^{H}}{\alpha^{L}-\theta \alpha^{H}}$ is the bubble size that maximizes the capital stock and output for any $t$. This non-linear relationship shows that small bubbles increase capital accumulation but that overly large bubbles are harmful to capital accumulation. An intuitive reason for this finding is simple. As long as the bubble size is small, an increase of bubble size raises the wealth level of the H-entrepreneurs but does not change the relation $r_{t}=q_{t+1} \alpha^{L}$. This wealth effect shifts savings from L-projects to H-projects. Thus, the crowd-in effect dominates at the margin and $K_{t+1} / Y_{t}$ is an increasing function of the size of bubbles. We call this the "Under-Sized Bubble Region." When the bubble size becomes equal to $\phi^{*}$, L-projects are not carried out at all. Once the bubble size becomes equal or larger than this $\phi^{*}$, an increase in bubbles raises the interest rate and crowds out the H-projects. Thus, $K_{t+1} / Y_{t}$ becomes a decreasing function of bubble size. We call this the "Over-Sized Bubble Region." 12

\subsection{Discussion}

Here, we explain in greater detail how our logic of the crowd-in effect of bubbles is related to the mechanisms of previous papers. As we have shown, the key factor for the expansionary effect of bubbles is that they reallocate funds toward $\mathrm{H}$-investments from L-investments. In a broad sense, these reallocation effects share the mechanism of such other papers as Farhi and Tirole (2012) and Martin and Ventura (2012, 2014). In Farhi and Tirole (2012), bubbles reallocate the funds from outside liquidity (less productive investment) to inside liquidity (more productive investment). However, the mechanism for the reallocation is different from our mechanism. In Farhi and Tirole, the change in the interest rate is crucial for the reallocation effect. Bubbles raise the supply of assets and, thus, the interest rate. A higher interest rate means a lower price of outside liquidity, and more funds can be allocated to

\footnotetext{
${ }^{12}$ In our 2012 January Version (Hirano and Yanagawa, January 2012 CIRJE DP 838), we showed that by using the non-monotonic relationship between the size of bubbles and capital stock (i.e., output), there exists a unique value of $\lambda$ that maximizes capital stock (output) in Proposition 8 in the section 4 . When we presented the 2012 January version at several places, we had a common comment from Kosuke Aoki, Fumio Hayashi, Nobuhiro Kiyotaki, Jianjun Miao, Kalin Nikolov, Harald Uhlig that output maximization does not necessarily correspond to welfare maximization. Thanks to the comment, we could proceed to a full welfare analysis for workers and entrepreneurs rigorously, which led to our April 2013 working paper (Hirano, Inaba, and Yanagawa, April 2013 CARF WP 268).
} 
more productive investment opportunities. On the other hand, in our paper, bubbles can be expansionary at the margin as long as $r_{t}=q_{t+1} \alpha^{L}$. Moreover, an increase in the bubble size raises $K_{t+1}$ under $r_{t}=q_{t+1} \alpha^{L}$. Since $q_{t+1}$ is a decreasing function of $K_{t+1}$, this means that the interest rate decreases by bubbles. Unlike Farhi and Tirole, even if the interest rate decreases by bubbles, sufficiently high rate of return on bubbles increases wealth of H-type entrepreneurs.

In our model, the reallocation is generated by the positive wealth effect of the $\mathrm{H}$ entrepreneurs. In this sense, our logic is related to that of Martin and Ventura (2012, 2014). ${ }^{13}$ In Martin and Ventura, it is assumed that in every period young agents who have a productive investment opportunity can create new bubbles. This assumption of the new bubble creation in every period generates the wealth effect or a collateral effect directly. However, there are crucial differences. First, Martin and Ventura assumed that no future return from investments is pledgeable, and thus, the leverage effect does not work. On the other hand, in our model, the H-entrepreneurs can gather more funds through the leverage multiplier, $1 /\left[1-\left(\theta q_{t+1} \alpha^{H} / r_{t}\right)\right]$, that is, even a small amount of an increase in the net worth by bubbles has a large increase effect on investment through the leverage multiplier. Second, we do not assume the new bubble creation in every period. Even if we abstract from the new bubble creation, our model generates the wealth effect. This is because, in our model, the bubbles are stochastic and agents are risk averse. Hence, the risk averse agents require high rate of return on bubble assets compared to the interest rate, and this high rate of return on bubbles increase entrepreneurs' wealth and generates the wealth effect.

\footnotetext{
${ }^{13}$ We thank an anonymous referee who noted this important point.
} 


$$
\phi_{t+1}=\frac{\frac{P_{t+1}}{P_{t}}}{\frac{A_{t+1}}{A_{t}}} \phi_{t} .
$$

${ }_{6}\left(1-p-\phi_{t}\right) /\left[\delta(\lambda)(1-p)-\phi_{t}\right]$ captures the risk premium on bubble assets. It follows that 7 if other things being equal, the risk premium is a decreasing function of $\lambda$. Using (20), (23),

$$
\phi_{t+1}=\left\{\begin{array}{cc}
\frac{\left(1-p-\phi_{t}\right)}{\delta(\lambda)(1-p)-\phi_{t}} & \text { if } \phi_{t} \leq \phi^{*}, \\
\frac{\theta}{\beta} \frac{\alpha^{H}-\alpha^{L}}{\delta(\lambda)(1-p)-(1-\theta) \phi_{t}} \phi_{t} & \\
\frac{1}{\alpha^{L}-\theta \alpha^{H}} p+\frac{[1-\delta(\lambda)](1-p)}{\delta(\lambda)(1-p)-\phi_{t}} \beta \phi_{t} & \text { if } \phi_{t}>\phi^{*} .
\end{array}\right.
$$
and the definition of aggregate wealth of entrepreneurs, (22) can be written as

Using this (24), we examine the sustainable dynamics of $\phi_{t}$. In order for bubbles to be sustainable, the following condition must be satisfied for any $t$, i.e., $\phi_{t}<1$. Violation of this condition means explosion of bubbles.

As examined in the literature (Tirole 1985; Farhi and Tirole 2012b), dynamics of bubbles takes three patterns. The first one is that bubbles become too large and explode to $\phi_{t} \geq 1$. This dynamic path cannot be sustained by this economy and thus, bubbles cannot exist in this pattern. The second pattern is that $\phi_{t}$ becomes smaller over time and converges to the 
steady-state of the bubbleless economy as long as bubbles persist. In this case, there exists a continuum of equilibria that converge to the bubbleless steady state, and this path is called asymptotically bubbleless. In this dynamic path, the effects of bubbles converge to zero. Hence, we exclude this path from our consideration as usual in the literature. The third pattern is that $\phi_{t}$ converges to a positive value as long as the bubbles persist. This path corresponds to the unique saddle path converging to a stochastic stationary-state where all variables $\left(K_{t}, A_{t}, q_{t}, r_{t}, w_{t}, P_{t}, \phi_{t}\right)$ become constant over time. In this paper, we focus on this saddle path equilibrium as usual in the literature, for example, Farhi and Tirole (2012b), and derive the dynamics of $\phi_{t}$. We prove the existence of the unique saddle path in the Appendix D.

The dynamic system of this economy is characterized by (21) and (24). However, (24) is independent from $K_{t}$ and the dynamics of $\phi_{t}$ is derived only by (24). From (24), we can derive that $\phi_{t}$ must be constant over time unless $\phi_{t}$ is asymptotically bubbleless. This means that on the saddle path, $\phi_{t}$ becomes constant over time, i.e., wealth of entrepreneurs and bubbles grow at the same rate. More precisely, under the existence condition of bubbles which will be explained below, $\phi_{t}=\phi$ for any $t$ on the saddle path and $\phi$ is a function of $\lambda: 14$

$$
\phi(\lambda)=\left\{\begin{array}{cl}
\delta(\lambda)-\frac{1-\delta(\lambda) \beta(1-p)}{\left[1+\left(\frac{\alpha^{H}-\alpha^{L}}{\alpha^{L}-\theta \alpha^{H}}\right) p\right] \beta-\beta(1-p)} & \\
\frac{1-\delta(\lambda) \beta(1-p)}{1-\frac{\alpha^{H}-\alpha^{L}}{\left[1+\left(\frac{\alpha^{L}-\theta \alpha^{H}}{\alpha^{L}}\right] \beta-\beta(1-p)\right.}}(1-p) & \text { if } 0 \leq \lambda \leq \lambda^{*}, \\
\frac{\delta(\lambda) \beta(1-p)-\theta}{\beta(1-\theta)} & \text { if } \lambda^{*}<\lambda \leq 1 .
\end{array}\right.
$$

$\lambda^{*}=\max [0, \hat{\lambda}]$, where $\hat{\lambda}$ is the value of $\lambda$ which achieves $\phi(\hat{\lambda})=\phi^{*}$, and it is explicitly

\footnotetext{
${ }^{14}$ In our model, if $\phi(\lambda) \leq 0$, no equilibrium with bubbles can exist. Not only stochastic stationary bubbles cannot exist, but also asymptotically bubbleless paths cannot exist.
} 
written as

$$
\hat{\lambda}=\frac{1}{1-\pi} \frac{\alpha^{L}[\beta(1-p)+(1-\beta+p \beta) \theta]-\theta \alpha^{H}[\beta+(1-\beta) \theta]}{\beta(1-p)\left(\alpha^{L}-\theta \alpha^{H}\right)}-\frac{\pi}{1-\pi} .
$$

It follows that $\hat{\lambda}$ is a decreasing function of $\pi, \alpha^{H} / \alpha^{L}$, and $\theta$, respectively. According to (25), we can derive the following Proposition 1 on the relationship between the size of bubbles, $\phi$ and expectations about government financial safety net, $\lambda$. Proofs of all the Propositions and Lemmas are in Appendix.

Proposition 1 On the saddle path equilibrium, $\phi$ increases with $\lambda$. That is, the size of bubbles increases as more government bailouts are guaranteed.

From (25) and Proposition 1, we learn that in a competitive equilibrium without government policy, i.e., $\lambda=0$, the size of bubbles does not necessarily equal to $\phi^{*}$. In other words, $\phi(\lambda=0)<\phi^{*}$, if the survival rate of bubbles, $\pi$, or the productivity difference between $\mathrm{H}$-and L-projects, $\alpha^{H} / \alpha^{L}$, or efficiency of the financial market, $\theta$, is relatively low. In those economies, if there is no government policy, even low-productivity entrepreneurs end up investing in equilibrium. The size of bubbles is striclty smaller than $\phi^{*}$, which means that under-sized bubbles arise. In this case, bailout expansions increase the size of bubbles and enhance production. Therefore, there exists a unique value of $\lambda=\hat{\lambda} \in(0,1)$ which achieves $\phi(\hat{\lambda})=\phi^{*}$. On the other hand, $\phi(\lambda=0) \geq \phi^{*}$, if $\pi$, or $\alpha^{H} / \alpha^{L}$, or $\theta$ is relatively high. In those economies, if there is no government policy, the size of bubbles is equal to or greater than $\phi^{*}$, which means that over-sized bubbles are created. The deriving process about $\phi(\lambda)$ and $\hat{\lambda}$ is explained in the Appendix F. Since negative $\lambda$ is infeasible, we mainly use $\lambda^{*}=\max [0$, $\hat{\lambda}]$ instead of $\hat{\lambda}$. We should mention that $\lambda^{*}$ is time-invariant, and we will show in the later section that $\lambda^{*}$ maximizes ex-ante production efficiency. 
Proposition 2 Stochastic bubbles can exist if and only if

$$
\theta<\delta(\lambda) \beta(1-p) \equiv \theta_{1}
$$

and

$$
\pi>\frac{\alpha^{L}-\theta \alpha^{H}}{\beta\left(\alpha^{L}-\theta \alpha^{H}\right)+p \beta\left(\alpha^{H}-\alpha^{L}\right)} \frac{1}{1-\lambda}-\frac{\lambda}{1-\lambda} \equiv \pi_{1},
$$

\section{Stochastic Stationary Equilibrium with Bubbles}

Next, we examine the existence conditions of stochastic bubbles. In other words, we investigate whether a dynamic path with bubbles does not explode. As we show below, expectations about government guarantees affect the prevailing conditions.

and

are satisfied. Under the conditions, $\phi_{t}=\phi$ for any $t$ and $\phi$ is a function of $\lambda$ as (25).

This Proposition 2 means that stochastic bubbles can arise if and only if bubbles are not too risky and when financial market imperfection is sufficiently severe. Intuitively, when $\pi$ is below a certain threshold $\pi_{1}$, bubbles are too risky to exist. In order to compensate entrepreneurs for their risk, they would need to grow so fast that they would become too large to be feasible in equilibrium. Moreover, in high $\theta$ regions where financial markets are sufficiently efficient, the interest rate becomes sufficiently high in the credit market and so does the rate of return on bubbles. Bubbles then grow so fast that the economy cannot sustain them. Thus, if $\theta$ is greater than $\theta_{1}$, bubbles cannot occur.

The important point is that both $\pi_{1}$ and $\theta_{1}$ depend on $\lambda$. In other words, expectations about government guarantees affect the existence conditions. We learn that $\pi_{1}$ is a decreasing function of $\lambda$, and $\theta_{1}$ is an increasing function of $\lambda$. In other words, bubble regions become wider with an increase in $\lambda$. This means that even too risky bubbles can arise once government guarantees are expected. In other words, the more government bailouts are guaranteed, the more likely riskier bubbles can occur. The intuition is that when bailouts are expected, the risk premium on bubble assets declines and thus the required rate of return also declines, because bubble assets become safer assets. As a result, the growth rate 

2 From (21), and (25), we have

with

$$
H(\lambda)= \begin{cases}\frac{\left(1+\frac{\alpha^{H}-\alpha^{L}}{\alpha^{L}-\theta \alpha^{H}} p\right) \beta \alpha^{L}-\beta \alpha^{L}(1-p)}{1-\delta(\lambda) \beta(1-p)} \sigma & \text { if } 0 \leq \lambda \leq \lambda^{*}, \\ \alpha^{H} \frac{\beta[1-\delta(\lambda)(1-p)]+(1-\beta) \theta}{1-\delta(\lambda) \beta(1-p)} \sigma & \text { if } \lambda^{*} \leq \lambda \leq 1 .\end{cases}
$$

3 As long as bubbles persist, the economy runs according to (26) and converges toward the 4 stochastic stationary state. An important point is that this $H(\lambda)$ function is independent 5 of time $t$. From this property, we can characterize the dynamics of $K$ simply. We see 6 that bubbly dynamics depends on $H(\lambda)$, which in turn depends on expectations about the 7 government's financial safety net, $\lambda$. We will explain later the property of $H(\lambda)$ in Lemma 81.

\section{Macro Effects of Anticipated Bailouts}

\subsection{Effects on Ex-ante Production Efficiency}

Bailouts may mitigate the adverse effects of bubbles' collapsing. However, once bailouts are expected, they may produce inefficiency ex-ante. To what extent are ex-post bailouts desirable from an ex-ante perspective? In this subsection, we analyze how expansions in government guarantees affect ex-ante production efficiency, which is defined as the production level at any date before the bubble bursts. From (25), we can easily imagine that $H$ is a non-linear function of $\phi$, which in turn is an increasing function of $\lambda$. Hence, the following Lemma 1 summarizes the property on $H(\lambda)$. 
Lemma $1 H(\lambda)$ increases with $\lambda$ in the region of $\lambda \in\left[0, \lambda^{*}\right)$, while it decreases with $\lambda$ in the region of $\lambda \in\left(\lambda^{*}, 1\right]$.

This lemma 1 reflects the fact that in the region of $\lambda \in\left[0, \lambda^{*}\right)$, where even L-types as well as H-types invest, a rise in $\lambda$ increases the size of bubbles, and this increased bubble size crowds in H-projects, while it crowds out L-projects, thereby increasing $H(\lambda)$. By contrast, in the region of $\lambda \in\left(\lambda^{*}, 1\right]$, where only H-types invest, a rise in $\lambda$ leads to large bubbles, which results in crowding out H-projects, thereby decreasing $H(\lambda)$.

From the perspective of ex-ante production efficiency, no-bailouts $(\lambda=0)$ and overly generous bailouts $\left(\lambda \in\left(\lambda^{*}, 1\right]\right)$ are undesirable if $\lambda^{*}$ is positive. That is, partial bailouts are desirable. On the other hand, no-bailouts are desirable if $\lambda^{*}=0$. We should mention that if $\hat{\lambda}$ is non-negative, $\lambda^{*}$ achieves $\phi^{*}$ and ex-ante production is maximized. However, if $\hat{\lambda}$ is negative, then $\phi^{*}$ cannnot be achieved and $\lambda^{*}$ maximizes ex-ante production efficiency under the constraint that $\lambda \geq 0$. Figure 2 illustrates the relationship between ex-post bailouts and ex-ante production efficiency when $\lambda^{*}$ is positive.

\subsection{Effects on Boom-Bust}

In this subsection, we discuss how anticipated bailouts affect boom-bust. Suppose that at date 0 (initial period), bubbles occur. Here, at date -1 , the economy is assumed to be in the steady state of a bubbleless economy. In Figure 3, the lines with $\lambda=\lambda^{*}$ is the boom-bust when bailouts are $\lambda^{*}$ (here we consider the case of $\lambda^{*}>0$ ), while the lines with $\lambda=0$ is the boom-bust with no-bailouts.

These charts in Figure 3 represent qualitative solutions, because we can work with the model analytically. ${ }^{15}$ Figure 3 shows that boom-bust is larger when $\lambda=\lambda^{*}$. When government bailouts are expected with a probability $\lambda^{*}$ at date 0 , L-types are willing to buy more bubble assets. Thus, bubble prices jump up in the initial period. Because of this increase in bubble prices, the net worth of H-types improves and their investments jump up too in

\footnotetext{
${ }^{15}$ In our model economy, bubbles may collapse at date 1 , date 2 , or date $3 \cdots$. In Figure 3 , we focus on the saddle path equilibrium, and present a sample path for which bubbles arise at date 0 under the expectations with $\lambda=\lambda^{*}$ and $\lambda=0$, and then collapse at any date $s$.
} 
the initial period, while the share of L-investments over aggregate savings $\left(Z_{0}^{L} / \beta A_{0}\right)$ falls to zero. That is, production efficiency improves. As a result, both output and the wage rate also rise in the next period (date 1). Moreover, the aggregate consumption of entrepreneurs jumps up in the initial period through the wealth effect of bubbles (i.e., the aggregate wealth of entrepreneurs rises together with the increase in bubble prices). All of these macroeconomic variables continue to rise over time until the bubble bursts. Since this is an asset pricing model, expected future increases in output are reflected in bubble prices in the initial period. Thus, bubble prices jump up largely at date 0 , which in turn improves the net worth of H-types and their investments substantially. A two-way feedback between bubble prices and output thus operates, which leads to a bubbly boom. Once bubbles collapse, all of those macroeconomic variables begin to fall sharply, and converge toward a new, lower, stationary steady-state of the bubbleless economy. ${ }^{16}$

Figure 3 shows that once bailouts are anticipated ex-ante, it ends up destabilizing the economy and requiring large amounts of public funds following the collapse of bubbles. We should mention that this instability comes from an improvement in resource allocation, namely, L-projects are crowded out and H-projects are crowded in. Thus, there might be a trade-off between the improvement in resource allocation and stability of the economy. In the next section, we conduct a full welfare analysis by considering this trade-off to examine optimal bailouts.

Here let us add a few remarks concerning boom-bust when $\lambda \in\left(\lambda^{*}, 1\right]$. In this region, the more bailouts are guaranteed, the more H-projects are crowded out, and the less productive activity is created. A rise in $\lambda$ therefore dampens both investment booms and output booms, and lowers the wage income. On the other hand, it raises bubble prices more and increases the consumption booms of entrepreneurs. These asymmetric impulse responses in the wage income and entrepreneurs' consumption suggest that in the region of $\lambda \in\left(\lambda^{*}, 1\right]$, overly large bubbles sustained by generous bailouts leads to increased inequality in average consumption

\footnotetext{
${ }^{16} \mathrm{We}$ assume that after a bubble bursts, its reappearing is not expected ex-ante. If its reappearing is expected ex-ante, the Diba-Grossman (1989) critique would apply and the price of the bubbly asset would always be positive since, even in periods in which the bubble has burst, agents would expect it to reappear with some probability. We thank an anonymous referee who noted this point.
} 


\section{Welfare Analysis}

\footnotetext{
${ }^{17}$ We get this asymmetric impulse response as long as $\beta$ is sufficiently larger than $\sigma$ (for example, $\beta=0.99$ and $\sigma=0.3$. As we will see in the next section 6 , inequality in welfare also widens.
} 
Let $V_{t}^{B B}\left(K_{t}\right)$ be the value function of taxpayers at date $t$ in the bubble economy. Let $V_{t}^{B L}\left(K_{t}\right)$ be the value function of taxpayers at date $t$ when bubbles collapse at date $t$ (see the Appendix $\mathrm{H}$ for detail examinations on $\left.V_{t}^{B L}\left(K_{t}\right)\right)$. Given the optimal decision rules, the Bellman equation can be written as

$$
V_{t}^{B B}\left(K_{t}\right)=\log c_{t}+\beta\left[\pi V_{t+1}^{B B}\left(K_{t+1}\right)+(1-\pi) V_{t+1}^{B L}\left(K_{t+1}\right)\right] .
$$

Solving the value function yields (see the Technical Appendix P for derivation.)

$$
\begin{array}{r}
V_{t}^{B B}\left(K_{t}\right)=\frac{1}{1-\beta \pi} \frac{\beta \sigma}{1-\beta \sigma} \log H(\lambda)+\frac{\beta(1-\pi)}{1-\beta \pi} M(\lambda) \\
+\frac{1}{1-\beta \pi} \log (1-\sigma)+\frac{\sigma}{1-\beta \sigma} \log K_{t} . \\
M(\lambda)=\log \left[1-\sigma-\lambda \frac{\beta \phi(\lambda)}{1-\beta \phi(\lambda)} \sigma\right]+\frac{\beta \sigma}{1-\beta \sigma} \log \left[1+\lambda \frac{\beta \phi(\lambda)}{1-\beta \phi(\lambda)}\right] \\
+\frac{\beta \sigma}{1-\beta \sigma} \frac{1}{1-\beta} \log \left[\left(1+\frac{\alpha^{H}-\alpha^{L}}{\alpha^{L}-\theta \alpha^{H}} p\right) \beta \alpha^{L} \sigma\right]+\frac{\beta}{1-\beta} \log (1-\sigma) .
\end{array}
$$


9 yields

$$
\frac{d V_{0}^{B B}}{d \lambda}=\frac{1}{1-\beta \pi} \frac{\beta \sigma}{1-\beta \sigma} \frac{d \log H(\lambda)}{d \lambda}+\frac{\beta(1-\pi)}{1-\beta \pi} \frac{d M(\lambda)}{d \lambda}
$$

where $\frac{d M(\lambda)}{d \lambda}<0$, i.e., the marginal ex-post effects by bailout expansions are negative, i.e., 2 the marginal increase in tax burden dominates the marginal increase in wage income (see the Appendix H). This leads to the following Lemma 2.

4 Lemma 2 Let $\lambda^{* *}$ be the value of $\lambda$ which maximizes $V_{0}^{B B}$. Since $\frac{d \log H(\lambda)}{d \lambda}<0$ in $\lambda \in\left(\lambda^{*}, 1\right]$ 5 from Lemma 1 and $\frac{d M(\lambda)}{d \lambda}<0, \frac{d V_{0}^{B B}}{d \lambda}<0$ in $\lambda \in\left(\lambda^{*}, 1\right]$. Thus, $\lambda^{* *} \notin\left(\lambda^{*}, 1\right]$.

$$
(1-p)[1-\beta \phi(\lambda=0)](1-\sigma)>\phi(\lambda=0)(1-\beta)[1-\pi \beta(1-p)] .
$$
optimal $\lambda$ for taxpayers never exists in the region where ex-ante production efficiency decreases.

Moreover, in the region of $\lambda \in\left[0, \lambda^{*}\right)$, we know from Lemma 1 that $H(\lambda)$ increases with $\lambda$, i.e., bailout expansions increase wage income by enhancing the crowding-in effect of bubbles. Thus, in $\lambda \in\left[0, \lambda^{*}\right)$, expansions in the government's financial safety net generate two competing effects. One is the welfare-enhancing effects captured by the first term of (28), i.e., the marginal gains from an increase in wage income. The other is the welfare-reducing effects captured by the second term of (28), i.e., the marginal costs by bailout expansions. Whether expansions in bailout guarantees increase taxpayers' welfare thus depends on which of these effects dominates.

Here let us assume $1-\beta \phi>1-\beta$, this assumption is more likely to be satisfied if $\sigma$ is small enough. The

This Lemma 2 means that too generous bailouts reduce taxpayers' welfare. Thus, the 
intuition is that, when $\sigma$ is small enough, wage income is large relative to tax burden for bailout per worker. As a result, the marginal costs by bailout expansions becomes sufficiently small and the marginal gains dominate. Using Lemma 2, we obtain the following Proposition 3.

Proposition 3 (i) If $\lambda^{*}>0$ and under (A1), $\lambda^{* *} \in\left(0, \lambda^{*}\right]$. That is, partial bailouts are optimal for taxpayers, i.e., no-bailouts $(\lambda=0)$ and overly generous bailouts $\left(\lambda \in\left(\lambda^{*}, 1\right]\right)$ are not optimal for taxpayers. (ii) If $\lambda^{*}=0, \lambda^{* *}=0$, i.e., no-bailouts are optimal for taxpayers.

From Proposition 3, we learn the following implications. In the economies where the survival rate of bubbles, $\pi$, or the productivity difference between $\mathrm{H}$-and L-projects, $\alpha^{H} / \alpha^{L}$, or efficiency of the financial market, $\theta$, is relatively low, then partial bailouts are optimal. Intuitively, in those economies, without bailouts, equilibrium bubble size is strictly smaller than $\phi^{*}$, and under-sized bubbles occur. In other words, even L-types end up investing and resource allocation is inefficient. In this situation, increasing financial safety net can improve resource allocation by encouraging risk-taking, thereby increasing welfare, but too generous financial safety net induces too much risk-taking and reduces welfare. By contrast, in the economies where $\pi$, or $\alpha^{H} / \alpha^{L}$, or $\theta$ is relatively high, no-bailouts are optimal. In those economies, even without bailouts, equilibrium bubble size is equal to or greater than $\phi^{*}$, and over-sized bubbles occur. In such a situation, expansions in financial safety net reduce welfare monotonically by crowding out productive investments.

Figure 4 illustrates numerical examples of Proposition 3-(i) showing the relationship between $V_{0}^{B B}$ and $\lambda$. When we compute $V_{0}^{B B}$, without loss of generality, we set an initial aggregate capital stock, $K_{0}$, to the steady-state value of the bubbleless economy. Other parameter values are shown in Table 1 . The only difference between the four cases lies in the bursting probability of the bubbles. The lower $\pi$ is, the riskier bubbles are. In the benchmark case and case 1 , bubbles are therefore relatively risky compared with case 2 and case 3 .

Figure 4 holds an important implication. In the benchmark case and case 1, taxpayers' welfare is maximized at $\lambda^{* *}$, which is lower than $\lambda^{*}$. Thus, the equilibrium where even L- 
types invest is optimal from a welfare perspective for taxpayers. This finding suggests that to maximize taxpayers' welfare, the government must sacrifice some efficiency in production. Put simply, in the case of riskier bubbles, L-types do not want to invest a large proportion of their savings in bubble assets, because the bursting probability is high. Therefore, they end up investing more savings in their own safe L-projects to hedge their risk. In such a situation, to crowd out L-projects completely, the government needs to commit to rescuing greater proportions of entrepreneurs (i.e., $\lambda^{*}=\hat{\lambda}$ is a decreasing function of $\pi$.), which directly increases the total bailout required. Moreover, when anticipated, such large-scale government bailouts create large bubbles, which increases the bailout transfer, too. These two effects require large amounts of public funds and increase workers' tax burden. Thus, welfare decreases with $\lambda$ in the region of $\lambda \in\left(\lambda^{* *}, 1\right]$ even before ex-ante production efficiency is maximized. By contrast, in case 2 and case 3 where the bursting probability of bubbles is lower (i.e., bubbles are relatively safer), ex-ante production efficiency is maximized by rescuing only smaller proportions of entrepreneurs, meaning that the total bailout required is lower. The welfare-enhancing effects thus dominate the welfare-reducing effects in all ranges of $\lambda \in\left(0, \lambda^{*}\right)$ and therefore, welfare is maximized at $\lambda=\lambda^{*}$.

The presented results show that the government faces a trade-off. When financial markets are imperfect, enough resources cannot be transferred to the productive sector and resource allocation is inefficient. Although the presence of the government's financial safety net can improve resource allocation by encouraging risk-taking, it also generates costs. Together with the improvement in resource allocation, large bubbles are created, which reduces welfare. In the case of riskier bubbles, the latter effect becomes too large. Thus, if the government aims to maximize taxpayers' welfare, it must sacrifice some production efficiency.

Moreover, as we show in Proposition 6 in the Appendix H, from an ex-post perspective (i.e., after the bubble bursts), no-bailouts are optimal for taxpayers. From this fact and Proposition 3, the difference between the ex-post and ex-ante welfare consequences for workers raises the possibility that a government that cared about workers would have a time-inconsistency problem. Interestingly, this time-inconsistency would go in the opposite 
direction as what is the usual assumption in the debate on bailouts. It is often thought that bailouts are optimal ex-post due to the costs of financial distress but not optimal ex-ante because the expectation of bailout gives bad incentives. Here it's the opposite: the expectation of bailouts can be helpful because it increases the value of liquid tradeable claims. Thus, bailouts are desirable from an ex-ante perspective. But once the time for delivering on the promise arrives, government would have an incentive to renege, meaning that bailouts are not desirable at all from an ex-post perspective.

\subsection{Welfare Effects for Entrepreneurs}

We next examine the welfare effects for entrepreneurs. From the detailed examinations in the Appendix J and the Technical Appendix R, we could derive value function for entrepreneurs, $W_{0}^{B B}$, explicitly, but it is hard to provide a full characterization analytically on the relationship between $W_{0}^{B B}$ and $\lambda$, here, we show numerical examples. Figure 5 illustrates the relationship in the benchmark parameter case, highlighting that welfare increases monotonically with $\lambda$. That is, the more bailouts are guaranteed, the more entrepreneurs gain. This result holds in cases 1-3, too. Moreover, even if over-sized bubbles arise in the Laissez-Faire economy, $W_{0}^{B B}$ monotonically increases with $\lambda$. Thus, in our numerical examples, $\lambda=1$ is optimal for entrepreneurs.

The result that entrepreneurs' welfare monotonically increases with expansions of bailouts comes from two reasons. Firstly, when bailouts are anticipated, it increases initial bubble prices. This enhances wealth effect of bubbles on their lifetime consumption, improving welfare. Secondly, government bailouts enhance consumption-smoothing effect for entrepreneurs. As the recent papers by Aoki et al. (2014) and Hirano and Yanagawa (2010) show, bubbles increase entrepreneurs' welfare, even if bubbles reduce output level by lowering long-run output growth rate and even if bubbles are expected to collapse. ${ }^{20}$ This is because, bubbles enhance consumption-smoothing effect. For entrepreneurs who face

\footnotetext{
${ }^{20} \mathrm{In}$ an endowment economy where financial market is completely shut down, Woodford (1990) show that government debt can function as an insurance device against endowment shocks, enhancing consumptionsmoothing effect.
} 

idiosyncratic productivity shocks, they cannot smooth their consumption because of the borrowing constraint. Since bubbles provide a high rate-of-return saving technology in the low-productivity state, the rate of return difference between the high-productivity state and the low-productivity state decreases by bubbles, which smooths their consumption. Government bailout policy increases this smoothing effect even further by providing an additional insurance device. Because of these two reasons, entrepreneurs' welfare increase with expansions of bailouts, even if bubbles decrease ex-ante production efficiency (see the Appendix $\mathrm{J}$ for more detail discussions.).

The fact that entrepreneurs' welfare monotonically increases with $\lambda$, wheres workers' welfare increases in $\lambda \in\left[0, \lambda^{* *}\right)$ and decreases in $\lambda \in\left(\lambda^{* *}, 1\right]$, suggests that as long as the bubble size is relatively small, bubbles increase everybody's welfare, but once the bubble size becomes too large sustained by generous bailout policy, bubbles lead to increased inequality in welfare between bubble holders and non-bubble holders as well as inequality in average consumption. ${ }^{21}$

In light of the above welfare analysis, in the economies where under-sized bubbles arise in the Laissez-Faire economy, the government's financial safety net can be Pareto-improving as long as $\lambda$ is relatively low. In our numerical analysis, the government's financial safety net makes all agents better off up to $\lambda=\lambda^{* *}$. Therefore, if the government chooses $\lambda$ according to the Pareto dominance criteria, $\lambda$ stops at $\lambda^{* *}{ }^{22}$ This holds an important implication for boom-bust. Figure 3 compares three cases of boom-bust, $\lambda=0, \lambda=\lambda^{*}$, and $\lambda=\lambda^{* *}$. The Figure 3 illustrates the case of $\lambda^{* *}<\lambda^{*}$. These charts show that in the case of $\lambda=\lambda^{* *}$, the boom-bust is milder than it is in the case of $\lambda=\lambda^{*}$, although production efficiency decreases compared with $\lambda=\lambda^{*} .^{23}$

\footnotetext{
${ }^{21}$ Stiglitz (2012) discusses how speculative activity including bubbles affects inequality between speculators and non-speculators.

${ }^{22}$ In $\lambda \in\left(\lambda^{* *}, 1\right]$, the winners from bailouts are entrepreneurs and the losers are taxpayers. The question is whether the entrepreneurs could compensate the taxpayers in a way that makes everyone better off. For example, in $\lambda \in\left(\lambda^{* *}, 1\right]$, if the government taxes the investment returns of entrepreneurs during the boom and gave the money to the workers, is this policy Pareto-improving? For workers, this transfer policy may improve their welfare, because the size of bubbles decreases and total bailout money becomes small. However, for entrepreneurs, welfare would decrease, because the initial wealth effects of consumption becomes small and the marginal rate of return from investment decreases.

${ }^{23}$ Of course, an actual $\lambda$ may change depending on the objectives of the government. For example, suppose
} 


\section{Discussion: Are Non-Stochastic Bubbles the Best?}

In this final section, we ask the following question: If the government could make stochastic bubbles non-stochastic bubbles with a bailout policy, would that be the best policy from a welfare perspective? ${ }^{24}$ Thus far, we have examined the effects of transfer policies from workers to loss-suffering entrepreneurs. However, instead of the transfer policies, we could consider a different bailout policy that uses government debt as a bailout tool. For example, consider an entrepreneur who holds bubble assets when the bubble collapses at date $t$. The government promises to hand out that entrepreneur government bonds. The bond prices are pegged to bubble prices on survival at date $t$. This bailout means that the government fully guarantees bubble investments against losses for all loss-suffering entrepreneurs. After date $t+1$, the government then simply rolls over the debt. ${ }^{25}$ If entrepreneurs are aware of this government's bailout plan, they expect bubble assets to deliver the same rate of return regardless of the realization of $\pi$. Bubble assets are thus considered to be risk-free, and so Ltypes no longer invest in their L-projects for risk-hedge. This policy restores entrepreneurs' net worth to what it would have been in the absence of the bubbles' bursting. The law of motion of the aggregate economy is thus the same as in the non-stochastic bubbly economy throughout the lifetime of the economy, not just after the bubble bursts, but also before the bursts. However, although this bailout policy has exactly the same effects as the government policy that makes stochastic bubbles non-stochastic ones, is this the best policy from a welfare perspective?

Moreover, the probability, $\pi$, might be affected by transfer policies from workers to losssuffering entrepreneurs. In this paper, we have assumed that $\pi$ is exogenously given and that workers were median voters. The objective of the government would be to maximize workers' welfare by setting $\lambda=\lambda^{* *}$. Alternatively, if the government aimed to maximize entrepreneurs' welfare for political reasons, then they would rescue all loss-suffering entrepreneurs by setting $\lambda=1$. In this case, overinvestment in bubbles would occur and a large bubble would arise. As a consequence, entrepreneurs gain, but taxpayers lose, leading to an increased inequality. Moreover, if the government's objective were to maximize ex-ante production efficiency, setting $\lambda=\lambda^{*}$ would be optimal; however it may not choose this $\lambda^{*}$ since a conflict of interest exists.

${ }^{24}$ We thank Nobuhiro Kiyotaki, Jean Tirole, and Harald Uhlig, because all of them point out this question.

${ }^{25}$ Government debt can be a substitute for privately created bubble assets. See Caballero and Krishnamurthy (2006), Kocherlakota (2009) for details. 


$$
\begin{aligned}
& \left.\frac{d V_{0}^{B B}}{d \pi}\right|_{\pi=1}=-\frac{\beta^{2} \sigma}{1-\beta \sigma} \frac{1}{p \beta+(1-\beta) \theta} \frac{(1-p)(1-\theta)}{1-\beta+p \beta} \\
& \quad+\frac{1}{(1-\beta)^{2}} \frac{\beta^{2} \sigma}{1-\beta \sigma}\left\{\log \left[\alpha^{H} \frac{p \beta+(1-\beta) \theta}{1-\beta+p \beta} \sigma\right]-\log \left[\left(1+\frac{\alpha^{H}-\alpha^{L}}{\alpha^{L}-\theta \alpha^{H}} p\right) \beta \alpha^{L} \sigma\right]\right\}
\end{aligned}
$$

(29) says that a rise in $\pi$ produces two competing effects on workers' welfare. If the bursting probability of bubbles falls, workers can earn higher wage incomes and consume more for longer periods, improving their levels of welfare. The second line of (29) captures this effect. The term in the brackets in the second line reflects the difference in wage income between the bubble economy and the bubbleless economy. On the other hand, with the increase in $\pi$, L-types are willing to buy more bubble assets, because bubble assets become safer. As a result, larger bubbles are created ( $\phi$ increases with $\pi$ ), which strengthens the crowding out effect of bubbles. This, in turn, reduces production, wage income, and consumption, lowering workers' welfare. The first line of (29) captures this effect. Under certain parameter values (see the Appendix K), the expansionary effects of bubbles are relatively small, namely the wage-income difference becomes sufficiently small. As a result, the crowding-out effect dominates the first effect. Thus, the sign of (29) becomes negative. This means that the 
following welfare ranking holds for workers:

$$
V_{0}^{B B}(\pi=1)<V_{0}^{B B}(\pi<1 \text { and } \lambda=0) .
$$

7 i.e., stochastic bubbles can be better than non-stochastic bubbles. ${ }^{26}$ This finding suggests that increasing the fragility of bubbles might actually enhance workers' welfare. The following Proposition summarizes this.

Proposition 4 From a welfare perspective of workers, stochastic bubbles can be better than non-stochastic bubbles, i.e., $\pi=1$ is not necessarily the best.

Moreover, we obtain the following Proposition.

Proposition 5 If $V_{0}^{B B}(\pi=1)<V_{0}^{B B}(\pi<1$ and $\lambda=0)$ and $\phi(\pi<1$ and $\lambda=0)<\phi^{*}$ and (A1) are satisfied, then we have the following welfare ranking: $V_{0}^{B B}(\pi=1)<V_{0}^{B B}(\pi<1$ and $\lambda=0)<V_{0}^{B B}(\pi<1$ and $\lambda>0)$.

We can prove numerically that there exists a set of parameters where Proposition 5 holds. $^{27}$ This Proposition 4 states that welfare under stochastic bubbles without bailouts is better than welfare under non-stochastic bubbles. Moreover, Propositon 5 states that welfare under stochastic bubbles with bailouts is better than welfare under stochastic bubbles without bailouts. This result is different from implications of Diamond and Dybvig (1983). In the Diamond and Dybvig model, bailout policy that uses deposit insurance can prevent bank runs. Thus, in equilibrium, bailout is never used, and this is the best policy. By contrast, in our model, the case where bubbles are expected to collapse with positive probabilities and workers are taxed for bailout can be desirable even for workers, rather than the case in which bubbles do not burst and workers are never taxed.

\footnotetext{
${ }^{26}$ This also means that in the case of a riskless bubble that is, $\pi=1, \phi>\phi^{*}$ holds, even if the bubble is expansionary in output. Hence, capital stock (i.e., output) is not maximized at any date $t$, not just in the steady state with bubbles, but also on the transitional path to the steady state with bubbles.

${ }^{27}$ For example, $\alpha^{H}=1.11, \alpha^{L}=1, \beta=0.96, \sigma=0.36, \theta=0.1, p=0.35, \pi=0.99973, \lambda=0.00001$.
} 


\section{Conclusion}

In this paper, we analyzed how anticipated bailouts affect the existence of stochastic bubbles, production efficiency, and boom-bust. Moreover, we examined the welfare consequences of such anticipated bailouts, and considered optimal bailout policies for taxpayers and for rescued entrepreneurs. Based on the presented analysis, we can draw the following conclusions.

Firstly, bailouts affect the existence conditions of stochastic bubbles. Even riskier bubbles can occur because of the existence of government guarantees.

Secondly, the relationship between bubble size and production level of the economy is non-monotonic, i.e., as long as bubble size is relatively small, bubbles increase production level, but once the size becomes too large, then bubbles reduce it. Given this non-monotonic relationship, we show that bailouts initially improve ex-ante efficiency in production by crowding in productive investments, while crowding out unproductive ones, but too generous bailouts lead to overinvestment in bubbles, which leads to strong crowding-out effects even on productive investments, thereby decreasing the production efficiency. In other words, bailouts have non-monotonic effects on ex-ante production efficiency. This suggests that there is a certain bailout level at which ex-ante production efficiency is maximized. Under the bailout policy, although the production efficiency is maximized, it may increase boombust and require large amount of public funds following the collapse of bubbles. This finding suggests a trade-off between economic stability and efficient resource allocation, which leads onto our third contribution.

Thirdly, we found that no-bailouts and full-bailouts are not optimal for taxpayers, i.e., partial bailouts are optimal for them. Moreover, in the case of riskier bubbles, to maximize taxpayers' welfare, the government must sacrifice some production efficiency to reduce the size of bubbles and soften boom-bust. In contrast, welfare for rescued entrepreneurs monotonically increases with the provision of bailouts. Our finding from the welfare analysis suggests that bailouts can be Pareto-improving from a welfare perspective.

Lastly, stochastic bubbles can be better than non-stochastic bubbles from the welfare perspective of taxpayers. This finding suggests that increasing the fragility of bubbles might 
actually enhance taxpayers' welfare.

In this paper, we focused on optimal ex-post bailouts by taking ex-ante effects into consideration. Future work could extend the presented analysis to additionally consider exante regulations such as leverage regulations or tax/subsidy policy on risky assets. It would also be interesting to examine the desirable policy mix from a welfare perspective.

\section{References}

[1] Aoki, Kosuke, and Kalin Nikolov. 2011. "Bubbles, Banks and Financial Stability," University of Tokyo.

[2] Aoki, Kosuke, Tomoyuki Nakajima, and Kalin Nikolov. 2014. "Safe Asset Shortage and Asset Price Bubbles," Journal of Mathematical Economics, 53(C): 164-174.

[3] Bernanke, Ben, and Mark Gertler. 1989. "Agency Costs, Net Worth, and Business Fluctuations," American Economic Review, 79(1): 14-31.

[4] Bernanke, Ben, Mark Gerlter, and Simon Gilchrist. 1999. "The Financial Accelerator in a Quantitative Business Cycle Framework," in J. Taylor and M. Woodford eds, the Handbook of Macroeconomics, 1341-1393. Amsterdam: North-Holland.

[5] Brunnermeier, Markus, and Yuliy Sannikov. 2011. "The I Theory of Money," mimeo, Princeton University.

[6] Caballero, Ricardo, and Arvind Krishnamurthy. 2006. "Bubbles and Capital Flow Volatility: Causes and Risk Management," Journal of Monetary Economics, 53(1): $35-53$.

[7] Diamond, Douglas, and Philip Dybvig. 1983. "Bank Runs, Deposit Insurance, and Liquidity," Journal of Political Economy, 91(3), 401-19.

[8] Diamond, Douglas, and Raghuram Rajan. 2012. "Illiquid Banks, Financial Stability, and Interest Rate Policy," Journal of Political Economy, 120(3), 552-91. 
[9] Diba, Behzad and Herschel Grossman. 1988. "The Theory of Rational Bubbles in Stock Prices" The Economic Journal, Vol. 98, No. 392 pp. 746-754

[10] Farhi, Emmanuel, and Jean Tirole. 2009. "Leverage and the Central Banker's Put," American Economic Review Papers and Proceedings, 99(2): 589-593.

[11] Farhi, Emmanuel, and Jean Tirole. 2012a. "Collective Moral Hazard, Maturity Mismatch and Systemic Bailouts," American Economic Review, 102(1): 60-93

[12] Farhi, Emmanuel, and Jean Tirole. 2012b. "Bubbly Liquidity," Review of Economic Studies, 79(2): 678-706.

[13] Gali, Jordi. 2014. "Monetary Policy and Rational Asset Price Bubbles," American Economic Review, 104(3): 721-752.

[14] Gertler, Mark, and Peter Karadi. 2011. "A Model of Unconventional Monetary Policy," Journal of Monetary Economics, 58(1): 17-34.

[15] Gerlter, Mark, and Nobuhiro Kiyotaki. 2010. "Financial Intermediation and Credit Policy in Business Cycle Analysis," In Friedman, B., and Woodford, M. eds, Handbook of Monetary Economics, 547-599. Elsevier, Amsterdam, Netherlands.

[16] Gertler, Mark, Nobuhiro Kiyotaki, and Albert Queralto. 2012. "Financial Crises, Bank Risk Exposure and Government Financial Policy," Journal of MonetaryEconomics, 59: $17-34$.

[17] Hellwig, Christian, and Guido Lorenzoni. 2009. "Bubbles and Self-Enforcing Debt," Econometrica, 77(4): 1137-1164.

[18] Hirano, Tomohiro, and Noriyuki Yanagawa. 2010. "Asset Bubbles, Endogenous Growth, and Financial Frictions," Working Paper, CARF-F-223, University of Tokyo.

[19] Hirano, Tomohiro, and Noriyuki Yanagawa. 2012(January). "Asset Bubbles and Bailout," CIRJE-F-838, CIRJE, University of Tokyo. 
[20] Hirano, Tomohiro, Masaru Inaba, and Noriyuki Yanagawa 2013(April). "Asset Bubbles and Bailouts," CARF-F-268, University of Tokyo.

[21] Holmstrom, Bengt, and Jean Tirole. 1998. "Private and Public Supply of Liquidity," Journal of Political Economy, 106(1): 1-40.

[22] Kiyotaki, Nobuhiro, 1998. "Credit and Business Cycles," The Japanese Economic Review, 49(1): 18-35.

[23] Kiyotaki, Nobuhiro, and John Moore. 1997. "Credit Cycles," Journal of Political Economy, 105(2): 211-248.

[24] Kiyotaki, Nobuhiro, and John Moore. 2008. "Liquidity, Business Cycles and Monetary Policy," Princeton University.

[25] Kocherlakota, R. Narayana. 1992. "Bubbles and Constraints on Debt Accumulation," Journal of Economic Theory, 57(1): 245-256.

[26] Kocherlakota, R. Narayana. 2009. "Bursting Bubbles: Consequences and Cures," University of Minnesota.

[27] Martin, Alberto, and Jaume Ventura. 2012. "Economic Growth with Bubbles," American Economic Review, 102(6): 3033-3058.

[28] Martin, Albert and Jaume Ventura. 2014. "The International Transmission of Credit Bubbles: Theory and Policy," presented at the 2014 JME-SNB-SCG Conference

[29] Matsuyama, Kiminori. 2007. "Credit Traps and Credit Cycles," American Economic Review, 97(1): 503-516.

[30] Miao, Jianjun, and Pengfei Wang. 2011. "Bubbles and Credit Constraints," mimeo, Boston University.

[31] Miao, Jianjun, Pengfei Wang, and Jing Zhou. 2014. "Housing Bubbles and Policy Analysis," mimeo, Boston University. 
[32] Roch, Francisco, and Harald Uhlig. 2012. "The Dynamics of Sovereign Debt Crises and Bailouts," Chicago University.

[33] Stiglitz, Joseph. 2012. The Price of Inequality: How Today's Divided Society Endangers Our Future. W. W. Norton \& Company.

[34] Tirole, Jean. 1985. "Asset Bubbles and Overlapping Generations," Econometrica, 53(6): 1499-1528.

[35] Uhlig, Harald (2010), "A Model of a Systemic Bank Run," Journal of Monetary Economics, 57(1): 78-96.

[36] Weil, Philippe. 1987. "Confidence and the Real Value of Money," Quarterly Journal of Economics, 102(1): 1-22.

[37] Woodford, Michael. 1990. "Public Debt as Private Liquidity," American Economic Review, 80(2): 382-388. 
Table 1: Parameters

\begin{tabular}{l|l|cccc}
\hline \multicolumn{2}{l|}{ Parameters } & benchmark & case 1 & case 2 & case 3 \\
\hline \hline & & & & & \\
$\alpha^{H}$ & productivity of high project & 1.15 & 1.15 & 1.15 & 1.15 \\
$\alpha^{L}$ & productivity of low project & 1 & 1 & 1 & 1 \\
$\beta$ & discount factor & 0.96 & 0.96 & 0.96 & 0.96 \\
$\sigma$ & capital share & 0.36 & 0.36 & 0.36 & 0.36 \\
$\theta$ & collateral ratio & 0.1 & 0.1 & 0.1 & 0.1 \\
$\pi$ & survival rate of bubbles & 0.99 & 0.992 & 0.994 & 0.996 \\
$p$ & probability for high project & 0.35 & 0.35 & 0.35 & 0.35
\end{tabular}




\section{A Workers' Maximization Problem}

2 The flow of funds constraint, the borrowing constraint, and short sale constraint for workers 3 are given by

$$
c_{t}^{u}+P_{t}\left(x_{t}^{u}-x_{t-1}^{u}\right)=w_{t}-r_{t-1} b_{t-1}^{u}+b_{t}^{u}-T_{t}^{u},
$$

$$
b_{t}^{u} \leq 0
$$

5

$$
x_{t}^{u} \geq 0
$$

\section{whe}

\section{of} the constraints (1)-(3), taking the bursting probability into consideration.

Next, we examine the optimal behavior of workers. Since the equilibrium interest rate becomes relatively low because of the borrowing constraint, saving through lending or buying bubbles is not an attractive behavior for workers. Thus, we can prove that they consume all their wage income in each period if there is no bailout policy. On the other hand, workers might save to smooth their consumption if the government uses a bailout policy. This is because, if bubbles collapse, workers have to pay tax to rescue entrepreneurs, which lowers their consumption, while if bubbles do not collapse, they do not have to pay this tax. So, consumption will be more volatile compared to the case without a bailout policy. Thus, workers may save if there is a bailout policy. In this paper, however, we focus on an equilibrium in which workers do not save, that is, $b_{t}^{u}=x_{t}^{u}=0$. We verify this in the Technical Appendix N that under certain parameter values, workers indeed do not save even 


\section{B Tax on entrepreneurs}

2 In the main text, we considered the case that the total bailout is financed by taxing workers.

3 In this Appendix, we consider a case that in order to finance bailout, the government taxes 4 not only workers, but also entrepreneurs who do not suffer losses from bubble investments.

${ }_{5}$ In this case, when bubbles collapse at date $t$, total bailout transfer, $\lambda P_{t} X$, is financed 6 through aggregate tax revenues from workers, $T_{t}^{u}$, and aggregate tax revenues from entre7 preneurs who do not suffer losses, $T_{t}^{e}$ :

$$
\lambda P_{t} X=T_{t}^{u}+T_{t}^{e}
$$

with

$$
\begin{aligned}
T_{t}^{e} & =\tau\left(q_{t} \alpha^{H} Z_{t-1}^{H}-r_{t-1} B_{t-1}^{H}\right) \\
& =\left\{\begin{array}{cc}
\tau \frac{\alpha^{H}(1-\theta) p}{\left(\alpha^{L}-\theta \alpha^{H}\right)[1-\phi(\lambda)]+\left(\alpha^{H}-\alpha^{L}\right) p} \sigma K_{t}^{\sigma} & \text { if } 0 \leq \lambda \leq \lambda^{*}, \\
\tau(1-\theta) \sigma K_{t}^{\sigma} & \text { if } \lambda^{*} \leq \lambda \leq 1,
\end{array}\right.
\end{aligned}
$$

where $\tau$ is a tax rate imposed on the date $t$ net worth of the non-loss-making entrepreneurs, (i.e., H-types in period $t-1$ ). For technical reasons, i,e., in order to derive entrepreneur's consumption function explicitly, we consider the case that the government taxes entrepreneur's net worth. $T_{t}^{e}$ increases with $\lambda$ in $0 \leq \lambda \leq \lambda^{*}$. This means that as $\lambda$ rises, aggregate H-investments expand during bubbly periods, which increases tax revenues from the nonloss-making entrepreneurs when bubbles collapse. This increase in tax revenues reduces tax burden for workers. When we solve for tax burden per unit of workers, $T_{t}^{u}$ (recall that there 
1 with

$$
F(\lambda)=\left\{\begin{array}{cl}
\lambda \frac{\beta \phi(\lambda)}{1-\beta \phi(\lambda)}-\tau \frac{\alpha^{H}(1-\theta) p}{\left(\alpha^{L}-\theta \alpha^{H}\right)[1-\phi(\lambda)]+\left(\alpha^{H}-\alpha^{L}\right) p} & \text { if } 0 \leq \lambda \leq \lambda^{*} \\
\lambda \frac{\beta \phi(\lambda)}{1-\beta \phi(\lambda)}-\tau(1-\theta) & \text { if } \lambda^{*} \leq \lambda \leq 1 .
\end{array}\right.
$$

2 It follows that $T_{t}^{u}$ is a decreasing function of $\tau$.

By using (4) and (5), $W(\lambda)$ is replaced with

$$
\begin{aligned}
M(\lambda) & =\log [1-\sigma-\sigma F(\lambda)]+\frac{\beta \sigma}{1-\beta \sigma} \log [1+F(\lambda)] \\
& +\frac{\beta \sigma}{1-\beta \sigma} \frac{1}{1-\beta} \log \left[\left(1+\frac{\alpha^{H}-\alpha^{L}}{\alpha^{L}-\theta \alpha^{H}} p\right) \beta \alpha^{L} \sigma\right]+\frac{\beta}{1-\beta} \log (1-\sigma) .
\end{aligned}
$$

From (27) together with (6), we see how an increase in $\tau$ affects workers' welfare. We learn that (27) is an increasing function of $\tau$, i.e., workers' welfare increases with $\tau$. Intuition is very simple. If the government imposes higher tax rate on the non-loss-making entrepreneurs, tax burden per unit of workers decreases, which increases workers' consumption when bubbles collapse, thereby improving their welfare. We also learn from (27) how an increase in bailout guarantees affects workers' welfare in this case. We find that even in this case, if (A1) holds, then partial bailouts are optimal for workers. Moreover, when we compute (27) with (6) under the benchmark parameter case, then we find that $\lambda^{* *}$ increases with $\tau$ and approaches $\lambda^{*}$. This means that optimal bailouts for workers approach the bailout level that maximizes ex-ante output efficiency. When the government taxes the non-loss-making entrepreneurs, tax revenues from those entrepreneurs increase together with an increase in $\lambda$, since $T_{t}^{e}$ is an increasing function of $\lambda$. This increase in tax revenues lowers tax burden for workers. As a result, the welfare-enhancing effect captured by the first term of (28) dominates the 


\footnotetext{
${ }^{28}$ This depends on the assumption that the arrival rate of H-projects is the same for every entrepreneur in every period. In effect, the identity of H-types and L-types is completely reshuffled in every period. As we have seen, this assumption greatly simplifies aggregation. At the aggregate level, then, distribution between H-types and L-types does not matter.

${ }^{29}$ Here we explain reasons why we don't consider a case where the government taxes entrepreneurs who suffer losses from bubble investments. One reason is that if the government taxes them, this means that the government not only bails them out, but also taxes them at the same time. In reality, when the government bails out economic agents, it will not tax them at the same time. The second reason is that by taxing loss-suffering entrepreneurs, the government may be able to discourage entrepreneurs' risk-taking. However, one of the points we want to emphasize in this paper is that rather than discouraging their risk-taking, encouraging it can make everyone better off.
} 
with

$$
T_{t}^{e}=\tau\left(q_{t} \alpha^{H} Z_{t-1}^{H}-r_{t-1} B_{t-1}^{H}\right)
$$

1 where $\tau$ is the tax rate imposed at date $t$ on the date $t$ net worth of the non-loss-making 2 entrepreneurs, (i.e., H-types in period $t-1) .{ }^{30}$

The date $t$ aggregate wealth of entrepreneurs after the transfer policy can be written as

$$
A_{t}=(1-\tau)\left(q_{t} \alpha^{H} Z_{t-1}^{H}-r_{t-1} B_{t-1}^{H}\right)+q_{t} \alpha^{L} Z_{t-1}^{L}-r_{t-1} B_{t-1}^{L}+\lambda P_{t} X
$$

The aggregate wealth of entrepreneurs at date $t$ is composed of two parts. The first term is the date $t$ aggregate net worth after tax of entrepreneurs who were H-types in period $t-1$. The second term is the date $t$ aggregate net worth including the bailout transfer of entrepreneurs who were L-types in period $t-1$. By using $(7)$, the above $A_{t}$ can be rearranged as

$$
A_{t}=q_{t} K_{t}+T_{t}^{u}
$$

3 It follows that $T_{t}^{u}$, namely, the transfer from workers to entrepreneurs, matters for the 4 aggregate wealth of entrepreneurs at date $t$ as well as the aggregate net worth of H-types 5 in period $t$. This finding lends support to why we consider transfer policies from workers to entrepreneurs. In this case, welfare implications remains unaffected. In the Appendix B, we explain this point more in depth.

\footnotetext{
${ }^{30}$ For technical reasons, i,e., in order to derive entrepreneur's consumption function explicitly, we consider the case that the government taxes entrepreneur's net worth.
} 


\section{Proof of the Existence of a Unique Saddle Path}

1 Given an initial capital stock, $K_{0}$, let $P_{0}^{\prime}$ be an initial bubble prices that satisfy $\frac{P_{0}^{\prime} X}{\beta\left(\sigma K_{0}^{\sigma}+P_{0}^{\prime} X\right)}=$ $\phi_{0}=\phi$

(i) If $P_{0}<P_{0}^{\prime}, \phi_{0}<\phi$, In this case, as long as bubbles persist, $\phi_{t}$ after date 1 becomes smaller over time and the economy asymptotically converges toward the bubbleless economy.

(ii) If $P_{0}>P_{0}^{\prime}, \phi_{0}>\phi$, In this case, $\phi_{t}$ after date 1 increases over time and the resulting path is unsustainable, because there is a positive probability that $\phi_{t}$ gets greater than one if bubbles persist long enough.

(iii) If $P_{0}=P_{0}^{\prime}, \phi_{0}=\phi$. This case corresponds to the saddle path. In this case, as long as bubbles persist, $\phi_{t}$ after date 1 becomes constant over time. Together with this constant $\phi_{t}$, the economy runs according to (26). When we solve for the steady-state capital stock from (26), we learn that there are two steady-state values. One is $K=0$. The other is $K(\lambda)>0$. Moreover, we learn $\frac{d K_{t+1}}{d K_{t}}>0, \frac{d^{2} K_{t+1}}{d K_{t}^{2}}<0, \frac{d K_{t+1}}{d K_{t}}\left(K_{t}=0\right)=\infty, \frac{d K_{t+1}}{d K_{t}}\left(K_{t}=K(\lambda)>0\right)=\sigma<$ 1. From these, we learn that if $P_{0}=P_{0}^{\prime}$, the stochastic steady state $K(\lambda)>0$ is globally saddle. Thus, if $P_{0}=P_{0}^{\prime}$, for any positive initial capital stock level, $K_{0}>0$, the economy runs according to (26) and converges to the stochastic steady-state $K(\lambda)>0$ until bubbles collapse. As long as the capital stock level converges to $K(\lambda)$, other variables, $A_{t}, q_{t}, r_{t}$, and $w_{t}$ must converge to constant levels. Moreover, $P_{t}$ converges to a positive value since $A_{t}$ converges to a positive value and $\phi$ is constant over time.

From (i), (ii), and (iii), we see that as in Farhi and Tirole (2012b), there exists a continuum of bubbly equilibria which can be supported as a rational expectations equilibrium and only one of them is the saddle path. 


\section{${ }_{22}$ E Proof of Proposition 1}

Differentiating (25) in $0 \leq \lambda \leq \lambda^{*}$ yields

$$
\begin{aligned}
\frac{d \phi(\lambda)}{d \lambda}= & \frac{(1-p)(1-\pi)}{\left[\left(1+\frac{\alpha^{H}-\alpha^{L}}{\alpha^{L}-\theta \alpha^{H}} p\right) \beta-1-\beta(1-p)[1-\delta(\lambda)]\right]^{2}} \\
& \quad \times\left[\left(1+\frac{\alpha^{H}-\alpha^{L}}{\alpha^{L}-\theta \alpha^{H}} p\right) \beta-1\right]\left[\left(1+\frac{\alpha^{H}-\alpha^{L}}{\alpha^{L}-\theta \alpha^{H}} p\right) \beta-\beta(1-p)\right]>0,
\end{aligned}
$$

because in the bubble regions, since $\phi(\lambda)>0$, the following inequality is satisfied:

$$
\left(1+\frac{\alpha^{H}-\alpha^{L}}{\alpha^{L}-\theta \alpha^{H}} p\right) \beta>\frac{1}{\delta(\lambda)}>1>\beta(1-p)>0 .
$$

In $\lambda^{*}<\lambda \leq 1$, differentiating (25) yields

$$
\frac{d \phi(\lambda)}{d \lambda}=\frac{\beta(1-p)(1-\pi)}{\beta(1-\theta)}>0
$$

\section{F Proof of Proposition 2}

2 From (24),

$$
\phi_{t+1}= \begin{cases}f\left(\phi_{t}\right) & \text { if } \phi_{t} \leq \phi^{*}, \\ g\left(\phi_{t}\right) & \text { if } \phi_{t}>\phi^{*},\end{cases}
$$

$3 \quad$ where $f\left(\phi_{t}\right) \equiv \frac{\frac{\left(1-p-\phi_{t}\right)}{\delta(\lambda)(1-p) \phi_{t}}}{\left(1+\frac{\left.\alpha^{H}-\alpha^{L} p\right)(1-p)}{\alpha^{L}-\theta \alpha^{H}} p\right) \beta+\frac{11-\delta(\lambda) \mid(1-p)}{\delta(\lambda)(1-p)-\phi_{t}} \beta \phi_{t}} \phi_{t}, g\left(\phi_{t}\right) \equiv \frac{\theta}{\beta} \frac{1}{\delta(\lambda)(1-p)-(1-\theta) \phi_{t}} \phi_{t}$, and $\phi^{*} \equiv \frac{\alpha^{L}(1-p)-\theta \alpha^{H}}{\alpha^{L}-\theta \alpha^{H}}$.

4 Note that if and only if $\theta<\frac{\alpha^{L}}{\alpha^{H}}(1-p)$, $\phi^{*}>0$. Moreover, $f\left(\phi^{*}\right)=g\left(\phi^{*}\right)$. We can easily 5 derive that $g^{\prime}>0$ and $g ">0$. Hence, if and only if $g^{\prime}(0)<1 \Leftrightarrow \theta<\delta(\lambda) \beta(1-p), g(\phi)=\phi$ 6 has a unique strictly positive solution, $\phi^{g}=\frac{\delta(\lambda) \beta(1-p)-\theta}{\beta(1-\theta)}>0 . f\left(\phi_{t}\right)$ function is rather complicated, but, by solving $f(\phi)=\phi$ explicitly, we can find that this equation has only two 
8 solutions, 0 and $\phi^{f}=\frac{\delta(\lambda)-\frac{1-\delta(\lambda) \beta(1-p)}{\left[1+\left(\frac{\alpha^{H}-\alpha^{L}}{\alpha^{L}-\theta \alpha^{H}}\right) p\right] \beta-\beta(1-p)}}{1-\frac{1-\delta(\lambda) \beta(1-p)}{\left[1+\left(\frac{\alpha^{H}-\alpha^{L}}{\alpha^{L}-\alpha^{H}}\right) p\right] \beta-\beta(1-p)}}(1-p)$. Furthermore $\phi^{f}>0$ if and only if $f^{\prime}(0)<1 \Leftrightarrow \theta>\frac{(1-\delta \beta) \alpha^{L}-p \beta \delta\left(\alpha^{H}-\alpha^{L}\right)}{\alpha^{H}(1-\delta \beta)}$.

(i-1) Obviously, if $\phi^{f} \leq 0$ and $\phi^{g} \leq 0$, bubbles cannot exist.

(i-2) Next, we examine the case where $\phi^{f} \leq 0$ and $\phi^{g}>0$. In this case $\phi^{g}$ is a candidate to realize $\phi_{t+1}=\phi_{t} \equiv \phi$. However, $\phi^{f} \leq 0$ means $f(\phi)>\phi$ for any positive $\phi$ and thus ${ }_{5} f\left(\phi^{*}\right)=g\left(\phi^{*}\right)>\phi^{*}$. It follows that $\phi^{g}<\phi^{*}$ and $\phi^{g} \neq \phi$. In other words, bubbles cannot exist.

(i-3) When $\phi^{f}>0$ and $\phi^{g} \leq 0, \phi^{f}$ is a candidate of $\phi$. In order that both $\phi^{g} \leq 0$ and $\phi^{*}>0$ are satisfied, $\delta \beta(1-p)<\theta<\frac{\alpha^{L}}{\alpha^{H}}(1-p)$ and $\delta \beta<\frac{\alpha^{L}}{\alpha^{H}}$ must be satisfied. However, when $\delta \beta<\frac{\alpha^{L}}{\alpha^{H}}, \theta<\frac{(1-\delta \beta) \alpha^{L}-p \beta \delta\left(\alpha^{H}-\alpha^{L}\right)}{\alpha^{H}(1-\delta \beta)}$ and $\phi^{f}$ cannot be strictly positive. Hence, there is a contradiction and bubbles cannot exist even in this case.

(i-4) Lastly, we examine the case where $\phi^{f}>0$ and $\phi^{g}>0$. This is the situation where $\frac{(1-\delta \beta) \alpha^{L}-p \beta \delta\left(\alpha^{H}-\alpha^{L}\right)}{\alpha^{H}(1-\delta \beta)}<\theta \leq \frac{\alpha^{L}}{\alpha^{H}}(1-p)<\delta(\lambda) \beta(1-p)$ or $\frac{(1-\delta \beta) \alpha^{L}-p \beta \delta\left(\alpha^{H}-\alpha^{L}\right)}{\alpha^{H}(1-\delta \beta)}<\frac{\alpha^{L}}{\alpha^{H}}(1-p)<$ $\theta<\delta(\lambda) \beta(1-p) . \phi^{*}>0$ is satisfied from $\theta<\frac{\alpha^{L}}{\alpha^{H}}(1-p)$. By defining that $\hat{\lambda}$ is the value of $\lambda$ that satisfies $\phi^{g}(\hat{\lambda})=\phi^{*}$, we can obtain that $\phi^{*}=g\left(\phi^{*}\right)=f\left(\phi^{*}\right)=\phi^{f}(\hat{\lambda})$. Since $\phi^{f}$ and $\phi^{g}$ are increasing functions of $\lambda, \phi^{f}(\lambda)<\phi^{*}$ and $\phi^{g}(\lambda)<\phi^{*}$ under $\lambda<\hat{\lambda}$. This means $\phi^{f}(\lambda)=\phi(\lambda)$ under $\lambda<\hat{\lambda}$. Similarly, $\phi^{f}(\lambda)>\phi^{*}$ and $\phi^{g}(\lambda)>\phi^{*}$ under $\lambda>\hat{\lambda}$, and we obtain that $\phi^{g}(\lambda)=\phi(\lambda)$ under $\lambda>\hat{\lambda}$. If $\hat{\lambda}<0, \phi^{f}(\lambda)>\phi^{*}$ and $\phi^{g}(\lambda)>\phi^{*}$ for any $\lambda$ and $\phi^{g}(\lambda)=\phi(\lambda)$. From these results, we can obtain (25). Moreover, if and ony if $\frac{(1-\delta \beta) \alpha^{L}-p \beta \delta\left(\alpha^{H}-\alpha^{L}\right)}{\alpha^{H}(1-\delta \beta)}<\theta<\delta(\lambda) \beta(1-p), \phi(\lambda)>0$ and stochastic bubbles can exist. The condition $\theta<\delta(\lambda) \beta(1-p) \equiv \theta_{1}$ is directly derived from the second inequality, and the condition $\pi>\frac{\alpha^{L}-\theta \alpha^{H}}{\beta\left(\alpha^{L}-\theta \alpha^{H}\right)+p \beta\left(\alpha^{H}-\alpha^{L}\right)} \frac{1}{1-\lambda}-\frac{\lambda}{1-\lambda} \equiv \pi_{1}$ can be derived from the first inequality. 


\section{G Proof of Lemma 1}

In $0 \leq \lambda<\lambda^{*}$, differentiating $H(\lambda)$ with respect to $\lambda$ yields

$$
\frac{d H(\lambda)}{d \lambda}=\frac{\left(1+\frac{\alpha^{H}-\alpha^{L}}{\alpha^{L}-\theta \alpha^{H}} p\right) \beta \alpha^{L}-\beta \alpha^{L}(1-p)}{[1-\delta(\lambda) \beta(1-p)]^{2}} \sigma \beta(1-p)(1-\pi)>0
$$

because in the bubble regions, since $\phi(\lambda)>0$, the following inequality is satisfied:

$$
\left(1+\frac{\alpha^{H}-\alpha^{L}}{\alpha^{L}-\theta \alpha^{H}} p\right) \beta>\frac{1}{\delta(\lambda)}>1>\beta(1-p)>0 .
$$

In $\lambda^{*}<\lambda \leq 1$, differentiating $H(\lambda)$ with respect to $\lambda$ yields

$$
\frac{d H(\lambda)}{d \lambda}=-\frac{\alpha^{H} \beta(1-p)(1-\pi) \sigma}{[1-\delta(\lambda) \beta(1-p)]^{2}}(1-\beta)(1-\theta)<0 .
$$

\section{H Value Function for Taxpayers}

2 Let us first examine whether bailouts are good for taxpayers after bubbles burst. Suppose that at date $t$, the bubble collapses (i.e., after date $t$, the economy is bubbleless). Whether 4 the government decides to bail out entrepreneurs at date $t$ depends on costs and benefits. 5 For instance, when bubbles collapse, workers have to pay the tax to rescue entrepreneurs,

Let $V_{t}^{B L}\left(K_{t}\right)$ be the value function of taxpayers at date $t$ when bubbles collapse. Given the optimal decision rules, the Bellman equation can be written as

$$
V_{t}^{B L}\left(K_{t}\right)=\log c_{t}+\beta V_{t+1}^{B L}\left(K_{t+1}\right)
$$


with

$$
\begin{gathered}
c_{t}=w_{t}-T_{t}^{u}, \\
c_{t}=w_{t} \text { after date } t+1 .
\end{gathered}
$$

1 Appendix $\mathrm{P}$ for derivation.)

$$
V_{t}^{B L}\left(K_{t}\right)=M(\lambda)+\frac{\sigma}{1-\beta \sigma} \log K_{t}
$$

with

$$
\begin{aligned}
M(\lambda)=\log [1-\sigma- & \left.\lambda \frac{\beta \phi(\lambda)}{1-\beta \phi(\lambda)} \sigma\right]+\frac{\beta \sigma}{1-\beta \sigma} \log \left[1+\lambda \frac{\beta \phi(\lambda)}{1-\beta \phi(\lambda)}\right] \\
& +\frac{\beta \sigma}{1-\beta \sigma} \frac{1}{1-\beta} \log \left[\left(1+\frac{\alpha^{H}-\alpha^{L}}{\alpha^{L}-\theta \alpha^{H}} p\right) \beta \alpha^{L} \sigma\right]+\frac{\beta}{1-\beta} \log (1-\sigma) .
\end{aligned}
$$

$T_{t}^{u}=\lambda P_{t} X$ is bailout per unit of workers. Solving the value function yields (see the Technical

To understand how bailout expansions affect taxpayers' welfare after the collapse of bubbles, we need to take $\phi(\lambda)$ as given. This is because, we're considering the bailout policy that changes a proportion of entrepreneurs rescued by the government, given the purchase prices of bubble assets (i.e., given $\phi(\lambda))$. Then, given $\phi(\lambda)$, the first term in $M(\lambda)$ captures the costs of the bailouts after the collapse of bubbles, while the second term captures the benefits. ${ }^{31}$ Then, we obtain the following Proposition.

Proposition 6 Suppose that a bubble collapses at date $t$. Given $\phi(\lambda)$, we have $\frac{\partial V_{t}^{B L}}{\partial \lambda}=$ $\frac{\partial M(\lambda)}{\partial \lambda}<0$, i.e., after bubbles' collapsing, bailout expansions reduce taxpayers' welfare monotonically. Thus, from an ex-post perspective, no-bailouts are optimal for taxpayers.

$31\left(1+\frac{\alpha^{H}-\alpha^{L}}{\alpha^{L}-\theta \alpha^{H}} p\right) \beta \alpha^{L} \sigma$ in $W(\lambda)$ is replaced with $\alpha^{H} \beta \sigma$ if $\alpha^{H} \geq \alpha^{L}(1-p) / \theta$. In our numerical examples, since we consider the case where $\lambda^{*}=\hat{\lambda}$ holds, $\alpha^{H}<\alpha^{L}(1-p) / \theta$ is satisfied. 
11

Proof. Given $\phi(\lambda)$, by differentiating equation (9) with respect to $\lambda$, we obtain

$$
\frac{d V_{t}^{B L}}{d \lambda}=\frac{-\sigma}{1-\sigma-\lambda \frac{\beta \phi(\lambda)}{1-\beta \phi(\lambda)} \sigma} \frac{\beta \phi(\lambda)}{1-\beta \phi(\lambda)}+\frac{\beta \sigma}{1-\beta \sigma} \frac{1}{1+\lambda \frac{\beta \phi(\lambda)}{1-\beta \phi(\lambda)}} \frac{\beta \phi(\lambda)}{1-\beta \phi(\lambda)}<0
$$

1 The first line is the marginal cost of bailout expansions, while the second line is the marginal 2 benefit. The above equation says that the marginal cost dominates the marginal benefit.

3 When we compute the value function in the initial period, the size of bubbles is affected 4 by expectations about government bailouts. So, we need to take into account the fact that ${ }_{5} \phi(\lambda)$ is an increasing function of $\lambda$. The following Lemma summarizes the property of $M(\lambda)$ 6 when we consider it.

7 Lemma 3 If we take into account the fact that $\phi(\lambda)$ is an increasing function of $\lambda$, we have $8 \frac{d V_{t}^{B L}}{d \lambda}=\frac{d M(\lambda)}{d \lambda}<0$.

Proof. By differentiating equation (9) with respect to $\lambda$, we obtain

$$
\begin{aligned}
& \frac{d V_{t}^{B L}}{d \lambda}=\frac{-\sigma}{1-\sigma-\lambda \frac{\beta \phi(\lambda)}{1-\beta \phi(\lambda)} \sigma}\left\{\frac{\beta \phi(\lambda)}{1-\beta \phi(\lambda)}+\frac{\lambda \beta}{[1-\beta \phi(\lambda)]^{2}} \frac{d \phi(\lambda)}{d \lambda}\right\} \\
& +\frac{\beta \sigma}{1-\beta \sigma} \frac{1}{1+\lambda \frac{\beta \phi(\lambda)}{1-\beta \phi(\lambda)}}\left\{\frac{\beta \phi(\lambda)}{1-\beta \phi(\lambda)}+\frac{\lambda \beta}{[1-\beta \phi(\lambda)]^{2}} \frac{d \phi(\lambda)}{d \lambda}\right\}<0
\end{aligned}
$$

We are now ready to compute the value function of taxpayers in the initial period (period $0)$. Let $V_{t}^{B B}\left(K_{t}\right)$ be the value function of taxpayers at date $t$ in the bubble economy. Given the optimal decision rules, the Bellman equation can be written as

$$
V_{t}^{B B}\left(K_{t}\right)=\log c_{t}+\beta\left[\pi V_{t+1}^{B B}\left(K_{t+1}\right)+(1-\pi) V_{t+1}^{B L}\left(K_{t+1}\right)\right]
$$

Solving the value function yields (27) (see the Technical Appendix P for derivation.). 


\section{${ }_{11}$ I Proof of Lemma 3}

In order to check the sign of (28), let us first consider the region of $\lambda \in\left(\lambda^{*}, 1\right]$. In this region, we know from Lemma 1 that $H(\lambda)$ decreases with $\lambda$. That is,

$$
\frac{d \log H(\lambda)}{d \lambda}<0
$$

1 We also know from the Lemma 3 in the Appendix $H$ that

$$
\frac{d M(\lambda)}{d \lambda}<0
$$

Taken together, we have

$$
\frac{d V_{0}^{B B}}{d \lambda}<0 \text { in } \lambda \in\left(\lambda^{*}, 1\right]
$$

\section{J Value Function for Entrepreneurs}

Let $W_{t}^{B B}\left(e_{t}, K_{t}\right)$ be the value function of the entrepreneur in the bubble economy who holds the net worth, $e_{t}$, at the beginning of period $t$. Since we have already derived decision rules, what we do here is that by using optimal decision rules, we compute expected indirect utility function of the entrepreneur evaluated at the time before the entrepreneur knows his/her type. When we compute the value function, we must take into account the survival probability of bubbles, the switching probability that the entreprenuer becomes H-type and L-type, and the bailout probability. Given the decision rules, the Bellman equation can be written as

$$
\begin{aligned}
& W_{t}^{B B}\left(e_{t}, K_{t}\right)=\log c_{t}+\beta \pi\left[p W_{t+1}^{B B}\left(R_{t}^{H} \beta e_{t}, K_{t+1}\right)+(1-p) W_{t+1}^{B B}\left(R_{t}^{L} \beta e_{t}, K_{t+1}\right)\right] \\
&+\beta(1-\pi)\left[\begin{array}{c}
p W_{t+1}^{B L}\left(R_{t}^{H} \beta e_{t}, K_{t+1}\right)+(1-p) \lambda W_{t+1}^{B L}\left(R_{t}^{L} \beta e_{t}, K_{t+1}\right) \\
+(1-p)(1-\lambda) W_{t+1}^{B L}\left(R_{t}^{L L} \beta e_{t}, K_{t+1}\right)
\end{array}\right],
\end{aligned}
$$


where $R_{t}^{H} \beta e_{t}, R_{t}^{L} \beta e_{t}$, and $R_{t}^{L L} \beta e_{t}$ are the net worth of the entrepreneur at date $t+1$ in each state. Note that the net worth of entrepreneurs evolves as $e_{t+1}=R_{t}^{j} \beta e_{t}$, where $j=H, L$, LL. $R_{t}^{H}, R_{t}^{L}$, and $R_{t}^{L L}$, which are given in the Technical Appendix $\mathrm{R}$, are realized rate of return per unit of saving from date $t$ to date $t+1$. $R_{t}^{H}$ corresponds to the leveraged rate of return on H-projects per unit of saving. $R_{t}^{L}$ is the rate of return per unit of saving for the entrepreneurs who were L-type at date $t$ conditional on bubbles' survive at date $t+1 . R_{t}^{L L}$ is realized rate of return per unit of saving for the entrepreneurs who were L-type at date $t$ conditional on bubbles' collapse in period $t+1$. When bubbles burst in period $t+1$, the realized rate of return per unit of saving decreases for L-types in period $t$, because all wealth they invested in bubble assets is wiped out. By contrast, for H-types in period $t$, since they did not purchase bubble assets in period $t$, the realized rate of return per unit of saving is not affected even by the bubble bursts.

Solving the value function yields (derivation is given in the Technical Appendix R.)

$$
W_{t}^{B B}\left(e_{t}, K_{t}\right)=m(\lambda)+\frac{\beta \sigma(\sigma-1)}{1-\beta \sigma} \frac{1}{1-\beta} \log K_{t}+\frac{1}{1-\beta} \log e_{t}(\lambda),
$$

where $m(\lambda)$ is given in the Technical Appendix R. The period $t$ net worth, $e_{t}$, in the third term increases with $\lambda$. When bailouts are expected, bubble prices and entrepreneurs' net worth jump up instantaneously, which increases their lifetime consumption. The third term captures this effect, which we call an initial wealth effects on consumption.

By setting $t=0$, we can understand how a rise in $\lambda$ affects entrepreneurs' welfare in the initial period. Since it is hard to provide a full characterization analytically on the relationship between $W_{0}^{B B}$ and $\lambda$, here, we show numerical examples. We will explain more details about procedures to derive numerical examples in the Technical Appendix S. Figure 5 illustrates the relationship in the benchmark parameter case, highlighting that welfare increases monotonically with $\lambda$. That is, the more bailouts are guaranteed, the more entrepreneurs gain. This result holds in cases 1-3, too. Moreover, even if over-sized bubbles arise in the Laissez-Faire economy, $W_{0}^{B B}$ monotonically increases with $\lambda$. Thus, in our numerical 
examples, $\lambda=1$ is optimal for entrepreneurs.

Intuition is the following. In the region of $\lambda \in\left[0, \lambda^{*}\right)$, a rise in $\lambda$ increases production before and after bubbles' collapse, which increases entrepreneurs' consumption. Moreover, because of the increase in bubble prices, the initial wealth effects on consumption is enhanced. Thus, entrepreneurs' consumption increases with $\lambda$ throughout the lifetime. In the region of $\lambda \in\left(\lambda^{*}, 1\right]$, although a rise in $\lambda$ leads to a large bubble and reduces production by enhancing the crowding-out effect of bubbles, welfare increases. The reasons are the followings. First, the initial wealth effects on consumption increases with $\lambda$. Moreover, bailout policy enhances consumption smoothing effect. As Aoki et al. (2014), and Hirano and Yanagawa (2010) showed, bubbles are welfare-improving, even if bubbles reduce a long-run output growth rate and even if bubbles are expected to collapse. This is because, bubbles provide a high rate-of-return saving vehicle in the low-productivity state. As a result, the rate-of-return difference between the high-productivity state and the low-productivity state becomes smaller with bubbles. This contributes to enhancing consumption smoothing effect. This means that in a borrowing constrained economy, bubbles provide an insurance for idiosyncratic productivity shocks to entrepreneurs. Government bailout policy enhances this consumption smoothing effect by providing another insurance device for entrepreneurs, i.e., the rate-of-return difference in each state decreases with $\lambda$. Hence, entrepreneurs' consumption increases even in $\lambda \in\left(\lambda^{*}, 1\right]$ where ex-ante production efficiency worsens with $\lambda$.

\section{K Proof of Proposition 4}

We need to prove that there exist parameter values under which stochastic bubbles can arise and the sign of (29) is negative.

First, we prove that there exist parameter values under which the sign of (29) is negative.

With regard to the second term of (29), when we solve for $\alpha^{H}$ that satisfies $\alpha^{H} \frac{p \beta+(1-\beta) \theta}{1-\beta+p \beta} \sigma=$ $\left(1+\frac{\alpha^{H}-\alpha^{L}}{\alpha^{L}-\theta \alpha^{H}} p\right) \beta \alpha^{L} \sigma$, then we obtain $\alpha^{H}=\frac{\alpha^{L}(1-\beta+p \beta)}{(1-\beta) \theta+p \beta}$ and $\frac{\alpha^{L} \beta(1-p)}{\theta}$. We focus on the case 


$$
\left(x_{t}^{i}\right): u^{\prime}\left(c_{t}^{i, \pi}\right)=E_{t}\left[u^{\prime}\left(\tilde{c}_{t+1}^{i}\right) \frac{P_{t+1}^{x}+\tilde{d}_{t+1}^{i}}{P_{t}}\right]
$$
the second term of (29), i.e., under $\alpha_{1}^{H}$, the sign of (29) is negative.

\section{Supplemental Material (Technical Appendices)} $x_{t}^{i}$ and $b_{t}^{i}$ are
W the

(1) (1)

where $0<\theta<\frac{p \beta^{2}(1-p)}{(1-\beta)(1-\beta+p \beta)+p \beta}$. In this case, $\frac{\alpha^{L}(1-\beta+p \beta)}{(1-\beta) \theta+p \beta}<\frac{\alpha^{L} \beta(1-p)}{\theta}$. If we pick up $\alpha_{1}^{H} \in$ $\left(\frac{\alpha^{L}(1-\beta+p \beta)}{(1-\beta) \theta+p \beta}, \frac{\alpha^{L} \beta(1-p)}{\theta}\right)$ that is sufficiently close to $\frac{\alpha^{L}(1-\beta+p \beta)}{(1-\beta) \theta+p \beta}$ or $\frac{\alpha^{L} \beta(1-p)}{\theta}$, then $\alpha^{H} \frac{p \beta+(1-\beta) \theta}{1-\beta+p \beta} \sigma$ is sufficiently close to $\left[1+\frac{\alpha^{H}-\alpha^{L}}{\alpha^{L}-\theta \alpha^{H}} p\right] \beta \alpha^{L} \sigma$. Thus, under $\alpha_{1}^{H}$, the first term of (29) dominates

Next, we prove that stochastic bubbles can arise under $\alpha_{1}^{H}$. If we characterize bubble regions with $\alpha^{H}$, stochastic bubbles can arise if and only if $\alpha^{H}>\frac{\alpha^{L}[1-\pi \beta(1-p)]}{(1-\pi \beta) \theta+p \beta \pi} \equiv \hat{\alpha}^{H}(\pi)$, where $\hat{\alpha}^{H}$ is a decreasing function of $\pi$ in $0<\pi \leq 1$ with $\hat{\alpha}^{H}=\frac{\alpha^{L}(1-\beta+p \beta)}{(1-\beta) \theta+p \beta}$ if $\pi=1$ (Note that if $\pi=1$, deterministic bubbles can arise in $\left.\alpha^{H} \geq \frac{\alpha^{L}(1-\beta+p \beta)}{(1-\beta) \theta+p \beta}\right)$. Thus, there exists a critical value of $\pi_{1}\left(\alpha_{1}^{H}\right)<1$ where stochastic bubbles can arise under $\alpha_{1}^{H}$ in $\pi \in\left(\pi_{1}\left(\alpha_{1}^{H}\right), 1\right]$.

\section{Derive the demand function for the bubble assets of an L-entrepreneur}

Each L-entrepreneur chooses optimal amounts of $b_{t}^{i}, x_{t}^{i}$, and $z_{t}^{i}$ so that the expected marginal utility from investing in three assets is equalized. The first order conditions with respect to

where $u(c)=\log c$ is the utility function of the entrepreneurs. With logarithmic preferences, the marginal utility is $u^{\prime}(c)=1 / c$. The expectation operator is taken over whether the bubble survives and whether the entrepreneur receives bailout transfer from the government. $\tilde{d}_{t+1}^{i}$, and $\tilde{c}_{t+1}^{i}$ are the stochastic variables, and $c_{t}^{i, \pi}$ is the optimal consumption level at date $t$ when 


$$
\left(b_{t}^{i}\right): \frac{1}{c_{t}^{i, \pi}}=E_{t}\left[\frac{r_{t}}{\tilde{c}_{t+1}^{i}}\right]=\pi \beta \frac{r_{t}}{c_{t+1}^{i, \pi}}+(1-\pi) \lambda \beta \frac{r_{t}}{c_{t+1}^{i,(1-\pi) \lambda}}+(1-\pi)(1-\lambda) \beta \frac{r_{t}}{c_{t+1}^{i,(1-\pi)(1-\lambda)}}
$$

2 where $c_{t+1}^{i, \pi}=(1-\beta)\left(q_{t+1} \alpha^{L} z_{t}^{i}-r_{t} b_{t}^{i}+P_{t+1} x_{t}^{i}\right)$ is the optimal consumption level at date ${ }_{3} t+1$ when bubbles survive at date $t+1, c_{t+1}^{i,(1-\pi) \lambda}=(1-\beta)\left(q_{t+1} \alpha^{L} z_{t}^{i}-r_{t} b_{t}^{i}+d_{t+1} x_{t}^{i}\right)$ is

bubbles persist at date $t$. Then (12) and (13) are rewritten as

$$
\left(x_{t}^{i}\right): \frac{1}{c_{t}^{i, \pi}}=E_{t}\left[\frac{1}{\tilde{c}_{t+1}^{i}} \frac{P_{t+1}^{x}+\tilde{d}_{t+1}^{i}}{P_{t}}\right]=\pi \beta \frac{P_{t+1}}{c_{t+1}^{i, \pi}}+(1-\pi) \lambda \beta \frac{d_{t+1}}{c_{t+1}^{i,(1-\pi) \lambda}}
$$

the optimal consumption level at date $t+1$ when bubbles collapse at date $t+1$ and the entrepreneur is rescued, and $c_{t+1}^{i,(1-\pi)(1-\lambda)}=(1-\beta)\left(q_{t+1} \alpha^{L} z_{t}^{i}-r_{t} b_{t}^{i}\right)$ is the optimal consumption level at date $t+1$ when bubbles collapse at date $t+1$ and the entrepreneur is not rescued. 32 The RHS of (14) is the gain in expected discounted utility from holding one additional unit of bubble assets at date $t+1$. With probability $\pi$ bubbles survive, in which case the entrepreneur can sell the additional unit at $P_{t+1}$, but with probability $1-\pi$ bubbles collapse, in which case with probability $\lambda$ he/she is rescued and receives $d_{t+1}$ units of consumption goods per unit of bubble assets, and with probability $1-\lambda$, he/she is not rescued and receives nothing. The denominators reflect the respective marginal utilities of consumption. Since we specifically consider a bailout policy that fully guarantees bubble investments against losses, $d_{t+1}=P_{t+1}>0$ if the agent $i$ is rescued when bubbles collapse at date $t+1$. The RHS of (15) is the gain in expected discounted utility from lending one additional unit. It is similar to the RHS of (14), except for the fact that lending yields $r_{t}$ at date $t+1$, irrespective of whether or not bubbles collapse.

From (16), (14), and (15), we can derive the demand function for bubble assets of an L-type in the main text, (17).

\footnotetext{
${ }^{32}$ Since the entrepreneur consumes a fraction $1-\beta$ of the current net worth in each period, the optimal consumption level at date $t+1$ is independent of the entrepreneur's type at date $t+1$. It only depends on whether bubbles collapse and whether government rescues the entrepreneur.
} 


\section{Aggregation}

The great merit of the expressions for each entrepreneur's investment and demand for bubble assets, $z_{t}^{i}$ and $x_{t}^{i}$, is that they are linear in period- $t$ net worth, $e_{t}^{i}$. Hence aggregation is easy: we do not need to keep track of the distributions.

From (16), we learn the aggregate H-investments:

$$
Z_{t}^{H}=\frac{\beta p A_{t}}{1-\frac{\theta q_{t+1} \alpha^{H}}{r_{t}}}
$$

where $A_{t} \equiv q_{t} K_{t}+P_{t} X$ is the aggregate wealth of entrepreneurs at date $t$, and $\sum_{i \in H_{t}} e_{t}^{i}=p A_{t}$ is the aggregate wealth of H-entrepreneurs at date $t$. From this investment function, we see that the aggregate $\mathrm{H}$-investments are both history-dependent and forward-looking, because they depend on asset prices, $P_{t}$, as well as cash flows from the investment projects in the previous period, $q_{t} K_{t}$. In this respect, this investment function is similar to the one in Kiyotaki and Moore (1997). There is a significant difference. In the Kiyotaki-Moore model, the investment function depends on land prices which reflect fundamentals (cash flows from land), while in our model, it depends on bubble prices.

Aggregate L-investments depend on the level of the interest rate:

$$
Z_{t}^{L}=\left\{\begin{array}{cl}
\beta A_{t}-\frac{\beta p A_{t}}{1-\frac{\theta \alpha}{\alpha^{L}}}-P_{t} X & \text { if } r_{t}=q_{t+1} \alpha^{L}, \\
0 & \text { if } r_{t}>q_{t+1} \alpha^{L} .
\end{array}\right.
$$

When $r_{t}=q_{t+1} \alpha^{L}$, L-entrepreneurs may invest positive amount. In this case, we know from (19) that aggregate L-investments are equal to aggregate savings of the economy minus aggregate $\mathrm{H}$-investments minus aggregate value of bubbles. When $r_{t}>q_{t+1} \alpha^{L}$, L-entrepreneurs do not invest. 


$$
P_{t} X_{t}=\frac{\delta(\lambda) \frac{P_{t+1}}{P_{t}}-r_{t}}{\frac{P_{t+1}}{P_{t}}-r_{t}} \beta(1-p) A_{t}
$$

1 where $\sum_{i \in L_{t}} e_{t}^{i}=(1-p) A_{t}$ is the aggregate net worth of L-entrepreneurs at date $t$. (18) is 2 the aggregate demand function for bubble assets at date $t$.

\section{N Worker's Behavior}

${ }_{4}$ We verify that workers do not save nor buy asset bubbles in equilibrium of the bubble 5 economy. First, we verify that workers do not save. When the borrowing constrained binds, 6 workers do not save. The condition that the borrowing constraint binds is

$$
\frac{1}{c_{t}^{u}}>\pi \beta \frac{r_{t}}{c_{t+1}^{u, \pi}}+(1-\pi) \beta \frac{r_{t}}{c_{t+1}^{u, 1-\pi}} .
$$

7 We know that $c_{t}^{u}=w_{t}$ and $c_{t+1}^{u, \pi}=w_{t+1}$ if workers do not save nor buy bubble assets. Then, 8 the above can be written as

$$
1>\left[\pi+(1-\pi) \frac{1-\sigma}{1-\sigma-\lambda \frac{\beta \phi(\lambda)}{1-\beta \phi(\lambda)} \sigma}\right] \beta \frac{K_{t}^{\sigma}}{K_{t+1}^{\sigma}} r_{t} .
$$

9 When $r_{t}=q_{t+1} \alpha^{L}$, (19) can be written as

$$
\frac{H(\lambda)}{\beta \sigma \alpha^{L}}>\pi+(1-\pi) \frac{1-\sigma}{1-\sigma-\lambda \frac{\beta \phi(\lambda)}{1-\beta \phi(\lambda)} \sigma} .
$$

Since $H(\lambda) / \beta \sigma \alpha^{L}>1$ in the bubble regions and the right hand side of (20) is an increasing function of $\sigma$ and converges to one when we take the limit of $\sigma \rightarrow 0$, (20) holds if $\sigma$ is sufficiently small. 
When $r_{t}=\theta q_{t+1} \alpha^{H}[1-\beta \phi(\lambda)] /[1-p-\phi(\lambda)],(20)$ can be written as

$$
\frac{H(\lambda)[1-p-\phi(\lambda)]}{\theta \beta \sigma \alpha^{H}[1-\phi(\lambda)]}>\pi+(1-\pi) \frac{1-\sigma}{1-\sigma-\lambda \frac{\beta \phi(\lambda)}{1-\beta \phi(\lambda)} \sigma} .
$$

Since $H(\lambda)[1-p-\phi(\lambda)] / \theta \beta \sigma \alpha^{H}[1-\phi(\lambda)]>1$ in the bubble regions and the right hand side of (21) is an increasing function of $\sigma$ and converges to one when we take the limit of $\sigma \rightarrow 0$, 3 (21) holds if $\sigma$ is sufficiently small. Under the reasonable parameter values in our numerical 4 examples, both (20) and (21) hold.

Next, we verify that workers do not buy bubble assets. When the short sale constraint binds, workers do not buy bubble assets. The condition that the short sale constraint binds is

$$
\frac{1}{c_{t}^{u}}>\pi \beta \frac{1}{c_{t+1}^{u, \pi}} \frac{P_{t+1}}{P_{t}}
$$

We know $c_{t}^{u}=w_{t}$ and $c_{t+1}^{u, \pi}=w_{t+1}$ if workers do not save nor buy bubble assets. Then, the above can be written as

$$
1>\pi \beta \frac{w_{t}}{w_{t+1}} \frac{P_{t+1}}{P_{t}}=\pi \beta
$$

5 which is true.

$6 \quad$ Likewise we can prove that workers do not save in equilibrium of the bubbleless economy 7 including at the time bubbles collapse.

\section{\& O Behavior of H-types}

$$
\frac{1}{c_{t}^{i}}>\beta E_{t}\left[\frac{1}{c_{t+1}^{i}} \frac{P_{t+1}}{P_{t}}\right]
$$




$$
\frac{1}{c_{t}^{i}}=\beta E_{t}\left[\frac{r_{t}}{c_{t+1}^{i}} \frac{q_{t+1} \alpha^{H}(1-\theta)}{r_{t}-\theta q_{t+1} \alpha^{H}}\right] .
$$

1 We also know that $c_{t+1}^{i}=(1-\beta)\left[\frac{r_{t} \alpha^{H}(1-\theta)}{r_{t}-\theta q_{t+1} \alpha^{H}}\right]$ if (22) is true. Inserting (23) into (22) yields

$$
\beta \frac{1}{c_{t+1}^{i}} \frac{r_{t}\left[q_{t+1} \alpha^{H}-\delta(\lambda) \frac{P_{t+1}}{P_{t}}\right]+\theta q_{t+1} \alpha^{H}\left[\delta(\lambda) \frac{P_{t+1}}{P_{t}}-r_{t}\right]}{r_{t}-\theta q_{t+1} \alpha^{H}}>0
$$

2 If (24) holds, then the short sale constraint binds. We see that the second term in the 3 numerator is positive as long as $\phi>0$ and we know that $\phi>0$ on the saddle path. Thus, if 4 the first term is positive, (24) holds. The condition that the first term is positive is

$$
q_{t+1} \alpha^{H}>\delta(\lambda) \frac{P_{t+1}}{P_{t}}
$$

5 On the saddle path, since $P_{t}$ follows according to

$$
P_{t}=\frac{\beta \phi(\lambda)}{X[1-\beta \phi(\lambda)]} \sigma K_{t}^{\sigma}
$$

6 Using (25), the above inequality condition can be written as

$$
\sigma \alpha^{H} K_{t}^{\sigma}>\delta(\lambda) K_{t+1}
$$

7 First, we show that (26) holds in $0 \leq \lambda \leq \lambda^{*}$. In $0 \leq \lambda \leq \lambda^{*}$, aggregate capital stock follows 8 (28). Thus, (26) can be written as

$$
\alpha^{H}>\delta(\lambda)\left[\left(1+\frac{\alpha^{H}-\alpha^{L}}{\alpha^{L}-\theta \alpha^{H}} p\right) \beta \alpha^{L}-\beta \alpha^{L} \phi(\lambda)\right] /[1-\beta \phi(\lambda)],
$$

9 which is equivalent to 


$$
\alpha^{H}>\delta(\lambda)\left[\left(1+\frac{\alpha^{H}-\alpha^{L}}{\alpha^{L}-\theta \alpha^{H}} p\right) \beta \alpha^{L}-\beta \alpha^{L}(1-p)\right] /[1-\delta(\lambda) \beta(1-p)] .
$$

The right hand side of (28) is an increasing and convex function of $\lambda$ in $0 \leq \lambda \leq \lambda^{*}$. Thus (26) holds in $0 \leq \lambda \leq \lambda^{*}$ if (26) is true at $\lambda=\lambda^{*}$. At $\lambda=\lambda^{*}$, we know $\phi=$ $\left[\alpha^{L}(1-p)-\theta \alpha^{H}\right] /\left(\alpha^{L}-\theta \alpha^{H}\right)$. Inserting this relation into (27) yields

$$
\alpha^{H}(1-\beta)+\frac{\alpha^{L} p \beta \alpha^{H}}{\alpha^{L}-\theta \alpha^{H}}\left[1-\delta\left(\lambda^{*}\right)\right]>0
$$

which is true.

Next, we show that (26) holds in $\lambda^{*} \leq \lambda \leq 1$. In $\lambda^{*} \leq \lambda \leq 1$, aggregate capital stock follows (28). Thus, (26) can be written as

$$
1-\beta \phi>\delta(\lambda) \beta(1-\phi)
$$

1 which is true, since $1-\beta \phi>1-\phi$ and $\delta(\lambda) \beta<1$.

\section{P Derivation of taxpayer's value function}

3 Suppose that at date $t$, bubbles collapse. After the date $t$, the economy is in the bubbleless

4 economy. Let $V_{t}^{B L}$ be the value function of taxpayers at date $t$ when bubbles collapse and 5 the government bails out entrepreneurs. First, we solve $V_{t+1}^{B L}$. Given the optimal decision 6 rules, the Bellman equation can be written as

$$
V_{t+1}^{B L}\left(K_{t+1}\right)=\log c_{t+1}+\beta V_{t+2}^{B L}\left(K_{t+2}\right), \text { after date } t+1,
$$


7 with

$$
\left\{\begin{array}{cc}
c_{t+1}=w_{t+1} & \text { after date } t+1 \\
K_{t+2}=\left[1+\frac{\alpha^{H}-\alpha^{L}}{\alpha^{L}-\theta \alpha^{H}} p\right] \beta \alpha^{L} \sigma K_{t+1}^{\sigma} & \text { after date } t+1 .
\end{array}\right.
$$

1 We guess that the value function is a linear function of $\log K$ :

$$
V_{t+1}^{B L}\left(K_{t+1}\right)=f+g \log K_{t+1} \quad \text { after date } t+1
$$

From (29)-(31), applying the method of undetermined coefficients yields

$$
\begin{gathered}
f=\frac{1}{1-\beta} \log (1-\sigma)+\frac{1}{1-\beta} \frac{\beta \sigma}{1-\beta \sigma} \log \left[\left(1+\frac{\alpha^{H}-\alpha^{L}}{\alpha^{L}-\theta \alpha^{H}} p\right) \beta \alpha^{L} \sigma\right], \\
g=\frac{\sigma}{1-\beta \sigma} .
\end{gathered}
$$

2 Thus, we have

$$
\begin{aligned}
V_{t+1}^{B L}\left(K_{t+1}\right)= & \frac{1}{1-\beta} \log (1-\sigma)+\frac{1}{1-\beta} \frac{\beta \sigma}{1-\beta \sigma} \log \left[\left(1+\frac{\alpha^{H}-\alpha^{L}}{\alpha^{L}-\theta \alpha^{H}} p\right) \beta \alpha^{L} \sigma\right] \\
& +\frac{\sigma}{1-\beta \sigma} \log K_{t+1}, \text { after date } t+1 .
\end{aligned}
$$

3 Next, we derive the value function of taxpayers at date $t$ when bubbles collapse and the 4 government bails out entrepreneur by taking into account the effects of bailouts on the date $5 t$ consumption and the date $t+1$ aggregate capital stock. The value function of taxpayers 6 at date $t$ satisfies

$$
V_{t}^{B L}\left(K_{t}\right)=\log c_{t}+\beta V_{t+1}^{B L}\left(K_{t+1}\right)
$$


7 with

$$
\left\{\begin{array}{c}
c_{t}=w_{t}-\lambda P_{t} X=w_{t}-\lambda \frac{\beta \phi(\lambda)}{1-\beta \phi(\lambda)} \sigma K_{t}^{\sigma}, \\
K_{t+1}=\left[1+\frac{\alpha^{H}-\alpha^{L}}{\alpha^{L}-\theta \alpha^{H}} p\right] \beta \alpha^{L} \sigma\left[1+\lambda \frac{\beta \phi(\lambda)}{1-\beta \phi(\lambda)}\right] K_{t}^{\sigma} .
\end{array}\right.
$$

1 From (32), (33), and (34), we have

$$
V_{t}^{B L}\left(K_{t}\right)=M(\lambda)+\frac{\sigma}{1-\beta \sigma} \log K_{t}
$$

2 Now, we are in a position to derive the value function at any date $t$ in the bubble economy.

3 Let $V_{t}^{B B}\left(K_{t}\right)$ be the value function of taxpayers at date $t$ in the bubble economy. Given 4 optimal decision rules, the Bellman equation can be written as

$$
V_{t}^{B B}\left(K_{t}\right)=\log c_{t}+\beta\left[\pi V_{t+1}^{B B}\left(K_{t+1}\right)+(1-\pi) V_{t+1}^{B L}\left(K_{t+1}\right)\right]
$$

5 with the optimal decision rule of aggregate capital stock until bubbles collapse:

$$
K_{t+1}=H(\lambda) K_{t}^{\sigma}
$$

6 We guess that the value function is a linear function of $\log K$ :

$$
V_{t}^{B B}\left(K_{t}\right)=s+Q \log K_{t}
$$

From (35), and (36)-(37), applying the method of undetermined coefficients yields

$$
\begin{gathered}
s=\frac{1}{1-\beta \pi} \log (1-\sigma)+\frac{\beta(1-\pi)}{1-\beta \pi} M(\lambda)+\frac{1}{1-\beta \pi} \frac{\beta \sigma}{1-\beta \sigma} \log H(\lambda), \\
Q=\frac{\sigma}{1-\beta \sigma} .
\end{gathered}
$$

7 Thus, we have (27). 


\section{Q Derivation of Assumption 1}

$$
\left.\frac{d V_{0}^{B B}}{d \lambda}\right|_{\lambda=0}=\frac{\beta^{2} \sigma(1-p)(1-\pi)}{(1-\beta \pi)(1-\beta \sigma)[1-\pi \beta(1-p)]}-\frac{\beta^{2} \sigma(1-\pi) \phi(\lambda=0)(1-\beta)}{(1-\beta \pi)[1-\beta \phi(\lambda=0)](1-\sigma)(1-\beta \sigma)}
$$

The first term is the marginal gains from bailout expansions, and the second term is the marginal costs. Then, the sign depends on

$$
\operatorname{sign}\left(\left.\frac{d V_{0}^{B B}}{d \lambda}\right|_{\lambda=0}\right)=\operatorname{sign}\{(1-p)[1-\beta \phi(\lambda=0)](1-\sigma)-\phi(\lambda=0)(1-\beta)[1-\pi \beta(1-p)]\}
$$

1 Thus, if Assumption 1 is satisfied, the marginal gains dominate the marginal costs.

\section{2 $R$ Derivation of entrepreneur's value function}

\section{з R.1 the case where the government does not tax entrepreneurs}

4 Suppose that at date $t$, bubbles collapse. After the date $t$, the economy is in the bubbleless 5 economy. Let $W_{t}^{B L}\left(e_{t}, K_{t}\right)$ be the value function of the entrepreneur at date $t$ who holds the net worth, $e_{t}$, at the beginning of the period $t$ before knowing his/her type of the period $t$.

7 First, we solve $W_{t+1}^{B L}\left(e_{t}, K_{t}\right)$. Given the optimal decision rules, the Bellman equation can be 8 written as

$$
W_{t+1}^{B L}\left(e_{t+1}, K_{t+1}\right)=\log c_{t+1}^{i}+\beta\left[\begin{array}{c}
p W_{t+2}^{B L}\left(R_{t+1}^{\prime H} \beta e_{t+1}, K_{t+2}\right) \\
+(1-p) W_{t+2}^{B L}\left(R_{t+1}^{\prime L} \beta e_{t+1}, K_{t+2}\right)
\end{array}\right] \text { after date } t+1
$$

9 where $R_{t+1}^{\prime H} \beta e_{t+1}$ and $R_{t+1}^{L L} \beta e_{t+1}$ are the date $t+2$ net worth of the entrepreneur when he/she was H-type and L-type at date $t+1$, respectively. $R_{t+1}^{\prime H}$ and $R_{t+1}^{L L}$ are realized rate of return per unit of saving from date $t+1$ to date $t+2$ in the bubbleless economy, and they satisfy

$$
\left\{\begin{array}{cc}
R_{t}^{\prime H}=\frac{q_{t+1} \alpha^{H}(1-\theta)}{1-\frac{\theta \alpha}{\alpha^{L}}} & \text { after date } t \\
R_{t}^{L}=q_{t+1} \alpha^{L} & \text { after date } t
\end{array}\right.
$$


Aggregate capital stock follows:

$$
K_{t+2}=\left(1+\frac{\alpha^{H}-\alpha^{L}}{\alpha^{L}-\theta \alpha^{H}} p\right) \beta \alpha^{L} \sigma K_{t+1}^{\sigma} \quad \text { after date } t+1
$$

1 We guess that the value function are linear functions of $\log K$ and $\log e$ :

$$
W_{t+1}^{B L}\left(e_{t+1}, K_{t+1}\right)=f_{1}+g_{1} \log K_{t+1}+h_{1} \log e_{t+1}
$$

2 From (39)-(42), applying the method of undetermined coefficients yields

$$
\begin{aligned}
f_{1}= & \frac{1}{1-\beta} \log (1-\beta)+\frac{\beta}{(1-\beta)^{2}} \log (1-\beta)+\frac{\beta}{(1-\beta)^{2}} \log \sigma \\
& +\frac{\beta}{(1-\beta)^{2}}\left[p \log \frac{\alpha^{H}(1-\theta)}{1-\frac{\theta \alpha^{H}}{\alpha^{L}}}+(1-p) \log \alpha^{L}\right] \\
& +\frac{\beta(\sigma-1)}{(1-\beta)^{2}} \frac{1}{1-\beta \sigma} \log \left[\left(1+\frac{\alpha^{H}-\alpha^{L}}{\alpha^{L}-\theta \alpha^{H}} p\right) \beta \alpha^{L} \sigma\right],
\end{aligned}
$$

$$
g_{1}=\frac{\beta \sigma}{1-\beta \sigma} \frac{\sigma-1}{1-\beta}
$$

4

$$
h_{1}=\frac{1}{1-\beta} .
$$

5 Next, we derive the value function at date $t$ when bubbles collapse and the government 6 bails out entrepreneurs by taking into account the effects of bailouts on the date $t+1$ 7 aggregate capital stock. Given the optimal decision rules, the value function at date $t$ 8 satisfies

$$
W_{t}^{B L}\left(e_{t}, K_{t}\right)=\log c_{t}+\beta\left[p W_{t+1}^{B L}\left(R_{t}^{\prime H} \beta e_{t}, K_{t+1}\right)+(1-p) W_{t+1}^{B L}\left(R_{t}^{\prime L} \beta e_{t}, K_{t+1}\right)\right]
$$


9 with

$$
K_{t+1}=\left[1+\frac{\alpha^{H}-\alpha^{L}}{\alpha^{L}-\theta \alpha^{H}} p\right] \beta \alpha^{L} \sigma\left[1+\lambda \frac{\beta \phi(\lambda)}{1-\beta \phi(\lambda)}\right] K_{t}^{\sigma} .
$$

1 From (42)-(47), we obtain

$W_{t}^{B L}\left(e_{t}, K_{t}\right)=f_{1}+\frac{\beta(\sigma-1)}{1-\beta} \frac{1}{1-\beta \sigma} \log \left[1+\lambda \frac{\beta \phi(\lambda)}{1-\beta \phi(\lambda)}\right]+\frac{\beta \sigma}{1-\beta \sigma} \frac{\sigma-1}{1-\beta} \log K_{t}+\frac{1}{1-\beta} \log e_{t}$.

Now, we are in a position to derive the value function at any date $t$ in the bubble economy. $W_{t}^{B B}\left(e_{t}, K_{t}\right)$ is the value function of the entrepreneur at any date $\mathrm{t}$ in the bubble economy who holds the net worth, $e_{t}$, at the beginning of the period $t$ before knowing his/her type of the period $t$. Given optimal decision rules, the Bellman equation can be written as

$$
\begin{gathered}
W_{t}^{B B}\left(e_{t}, K_{t}\right)=\log c_{t}+\beta \pi\left[p W_{t+1}^{B B}\left(R_{t}^{H} \beta e_{t}, K_{t+1}\right)+(1-p) W_{t+1}^{B B}\left(R_{t}^{L} \beta e_{t}, K_{t+1}\right)\right] \\
+\beta(1-\pi)\left[\begin{array}{c}
p W_{t+1}^{B L}\left(R_{t}^{H} \beta e_{t}, K_{t+1}\right)+(1-p) \lambda W_{t+1}^{B L}\left(R_{t}^{L} \beta e_{t}, K_{t+1}\right) \\
+(1-p)(1-\lambda) W_{t+1}^{B L}\left(R_{t}^{L L} \beta e_{t}, K_{t+1}\right)
\end{array}\right],
\end{gathered}
$$

2 where $R_{t}^{H} \beta e_{t}, R_{t}^{L} \beta e_{t}$, and $R_{t}^{L L} \beta e_{t}$ are the date $t+1$ net worth of the entrepreneur in each 3 state. $R_{t}^{H}, R_{t}^{L}$, and $R_{t}^{L L}$ are realized rate of return per unit of saving from date $t$ to date ${ }_{4} t+1$, and in $0 \leq \lambda \leq \lambda^{*}$, they satisfy

$$
\left\{\begin{array}{c}
R_{t}^{H}=\frac{q_{t+1} \alpha^{H}(1-\theta)}{1-\frac{\theta^{H} H}{\alpha^{L}}} \\
R_{t}^{L}=\delta(\lambda) \frac{P_{t+1}}{P_{t}}=\delta(\lambda) \frac{q_{t+1} \alpha^{L}[1-p-\phi(\lambda)]}{\delta(\lambda)(1-p)-\phi(\lambda)} \\
R_{t}^{L L}=\frac{q_{t+1} \alpha^{L}[1-p-\phi(\lambda)]}{1-p}
\end{array}\right.
$$


${ }_{5}$ and in $\lambda^{*} \leq \lambda \leq 1$, they satisfy

$$
\left\{\begin{array}{c}
R_{t}^{H}=\frac{q_{t+1} \alpha^{H}(1-\theta)[1-\phi(\lambda)]}{p} \\
R_{t}^{L}=\delta(\lambda) \frac{P_{t+1}}{P_{t}}=\delta(\lambda) \frac{q_{t+1} \theta \alpha^{H}[1-\phi(\lambda)]}{\delta(\lambda)(1-p)-\phi(\lambda)} \\
R_{t}^{L L}=\frac{q_{t+1} \theta \alpha^{H}[1-\phi(\lambda)]}{1-p}
\end{array}\right.
$$

1 Aggregate capital stock until bubbles collapse follows:

$$
K_{t+1}=H(\lambda) K_{t}^{\sigma}
$$

2 We guess that the value function are linear functions of $\log K$ and $\log e$ :

$$
W_{t}^{B B}\left(e_{t}, K_{t}\right)=m+l \log K_{t}+n \log e_{t}
$$

3 From (48)-(53), and (49), applying the method of undetermined coefficients yields

$$
\begin{gathered}
m=\frac{1}{1-\beta \pi} \log (1-\beta)+\frac{1}{1-\beta \pi} \frac{\beta}{1-\beta} \log \beta+\frac{1}{1-\beta \pi} \frac{\beta}{1-\beta} \log \sigma \\
+\frac{\beta(\sigma-1)}{1-\beta \pi} \frac{1}{1-\beta \sigma} \frac{1}{1-\beta} \log H(\lambda) \\
+\frac{\beta(1-\pi)}{1-\beta \pi}\left\{f_{1}+\frac{\beta(\sigma-1)}{1-\beta} \frac{1}{1-\beta \sigma} \log \left[1+\lambda \frac{\beta \phi(\lambda)}{1-\beta \phi(\lambda)}\right]\right\} \\
+\frac{1}{1-\beta \pi} \frac{\beta}{1-\beta}\left[\pi J_{1}+(1-\pi) J_{2}\right] \\
l=\frac{\beta \sigma(\sigma-1)}{1-\beta \sigma} \frac{1}{1-\beta}, \\
n=\frac{1}{1-\beta},
\end{gathered}
$$

4 where in $0 \leq \lambda \leq \lambda^{*}$, 


$$
J_{1}=p \log \frac{\alpha^{H}(1-\theta)}{1-\frac{\theta \alpha^{H}}{\alpha^{L}}}+(1-p) \log \left[\delta(\lambda) \frac{\alpha^{L}[1-p-\phi(\lambda)]}{\delta(\lambda)(1-p)-\phi(\lambda)}\right]
$$

$$
\begin{aligned}
J_{2}= & p \log \frac{\alpha^{H}(1-\theta)}{1-\frac{\theta \alpha^{H}}{\alpha^{L}}}+(1-p) \lambda \log \left[\delta(\lambda) \frac{\alpha^{L}[1-p-\phi(\lambda)]}{\delta(\lambda)(1-p)-\phi(\lambda)}\right] \\
& +(1-p)(1-\lambda) \log \left[\frac{\alpha^{L}[1-p-\phi(\lambda)]}{1-p}\right]
\end{aligned}
$$

and in $\lambda^{*} \leq \lambda \leq 1$,

$$
J_{1}=p \log \frac{\alpha^{H}(1-\theta)[1-\phi(\lambda)]}{p}+(1-p) \log \left[\delta(\lambda) \frac{\theta \alpha^{H}[1-\phi(\lambda)]}{\delta(\lambda)(1-p)-\phi(\lambda)}\right]
$$

$$
\begin{aligned}
J_{2}= & p \log \frac{\alpha^{H}(1-\theta)[1-\phi(\lambda)]}{p}+(1-p) \lambda \log \left[\delta(\lambda) \frac{\theta \alpha^{H}[1-\phi(\lambda)]}{\delta(\lambda)(1-p)-\phi(\lambda)}\right] \\
& +(1-p)(1-\lambda) \log \left[\frac{\theta \alpha^{H}[1-\phi(\lambda)]}{1-p}\right]
\end{aligned}
$$

2 Thus, we have (11).

\section{R.2 the case where the government taxes entrepreneurs}

4 When the government taxes entrepreneurs who do not suffer losses from bubble investments, ${ }_{5} m$ and $J_{2}$ change as follows:

$$
\begin{aligned}
m= & \frac{1}{1-\beta \pi} \log (1-\beta)+\frac{1}{1-\beta \pi} \frac{\beta}{1-\beta} \log \beta+\frac{1}{1-\beta \pi} \frac{\beta}{1-\beta} \log \sigma \\
& +\frac{\beta(\sigma-1)}{1-\beta \pi} \frac{1}{1-\beta \sigma} \frac{1}{1-\beta} \log H(\lambda) \\
& +\frac{\beta(1-\pi)}{1-\beta \pi}\left\{f_{1}+\frac{\beta(\sigma-1)}{1-\beta} \frac{1}{1-\beta \sigma} \log [1+F(\lambda)]\right\} \\
& +\frac{1}{1-\beta \pi} \frac{\beta}{1-\beta}\left[\pi J_{1}+(1-\pi) J_{2}\right],
\end{aligned}
$$


${ }_{6}$ in $0 \leq \lambda \leq \lambda^{*}$

$$
\begin{aligned}
J_{2}= & p \log \frac{(1-\tau) \alpha^{H}(1-\theta)}{1-\frac{\theta \alpha^{H}}{\alpha^{L}}}+(1-p) \lambda \log \left[\delta(\lambda) \frac{\alpha^{L}[1-p-\phi(\lambda)]}{\delta(\lambda)(1-p)-\phi(\lambda)}\right] \\
& +(1-p)(1-\lambda) \log \left[\frac{\alpha^{L}[1-p-\phi(\lambda)]}{1-p}\right] .
\end{aligned}
$$

${ }_{1}$ in $\lambda^{*} \leq \lambda \leq 1$,

$$
\begin{aligned}
J_{2}= & p \log \frac{(1-\tau) \alpha^{H}(1-\theta)[1-\phi(\lambda)]}{p}+(1-p) \lambda \log \left[\delta(\lambda) \frac{\theta \alpha^{H}[1-\phi(\lambda)]}{\delta(\lambda)(1-p)-\phi(\lambda)}\right] \\
& +(1-p)(1-\lambda) \log \left[\frac{\theta \alpha^{H}[1-\phi(\lambda)]}{1-p}\right] .
\end{aligned}
$$

S Procedures to derive numerical examples of entrepreneur's welfare

When we compute (11), we make the following assumptions: aggregate capital stock in the initial period is set to the steady-state value of the bubbleless economy; population measure of entrepreneurs is assumed to be equal to one; in the initial period, each entrepreneur is endowed with the same amount of capital, $k_{t}^{i}=k_{t}$, and one unit of bubble assets, and owes no debt. Under these assumptions, all entrepreneurs hold the same amount of net worth in the initial period, i.e., $e_{0}=q_{0} k_{0}+P_{0}$. By using determination of equilibrium bubble prices (25), $e_{0}$ can be written as

$$
e_{0}(\lambda)=\frac{1}{1-\beta \phi(\lambda)} \sigma K_{0}^{\sigma}
$$

Inserting the above relation into (11) yields

$$
W_{0}^{B B}\left(K_{0}\right)=m(\lambda)+\frac{1}{1-\beta} \log \sigma+\frac{1}{1-\beta \sigma} \log K_{0}-\frac{1}{1-\beta} \log [1-\beta \phi(\lambda)] .
$$


${ }_{4}$ Figure 5 describes the relationship between $W_{0}^{B B}$ and $\lambda$. 
Figure 1

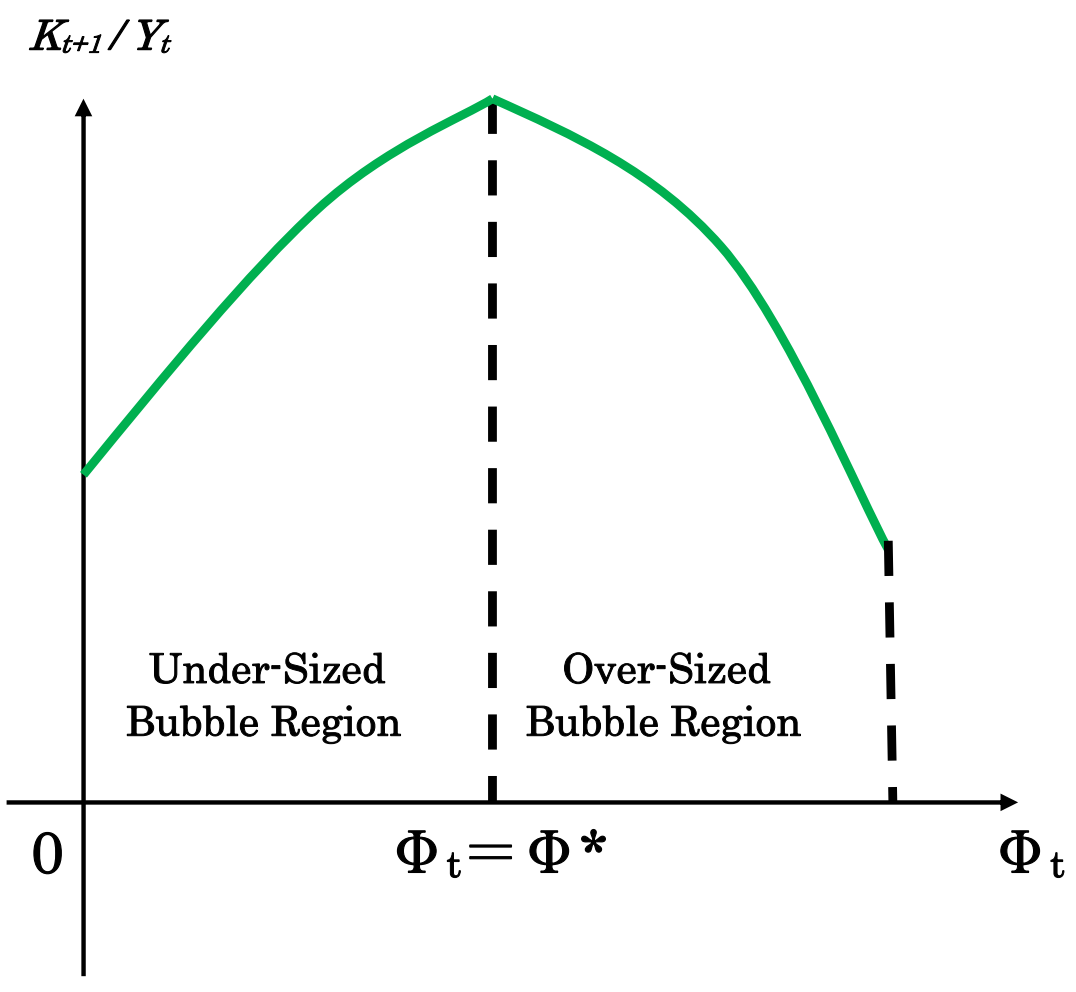

Figure 2

Ex-ante Production Efficiency

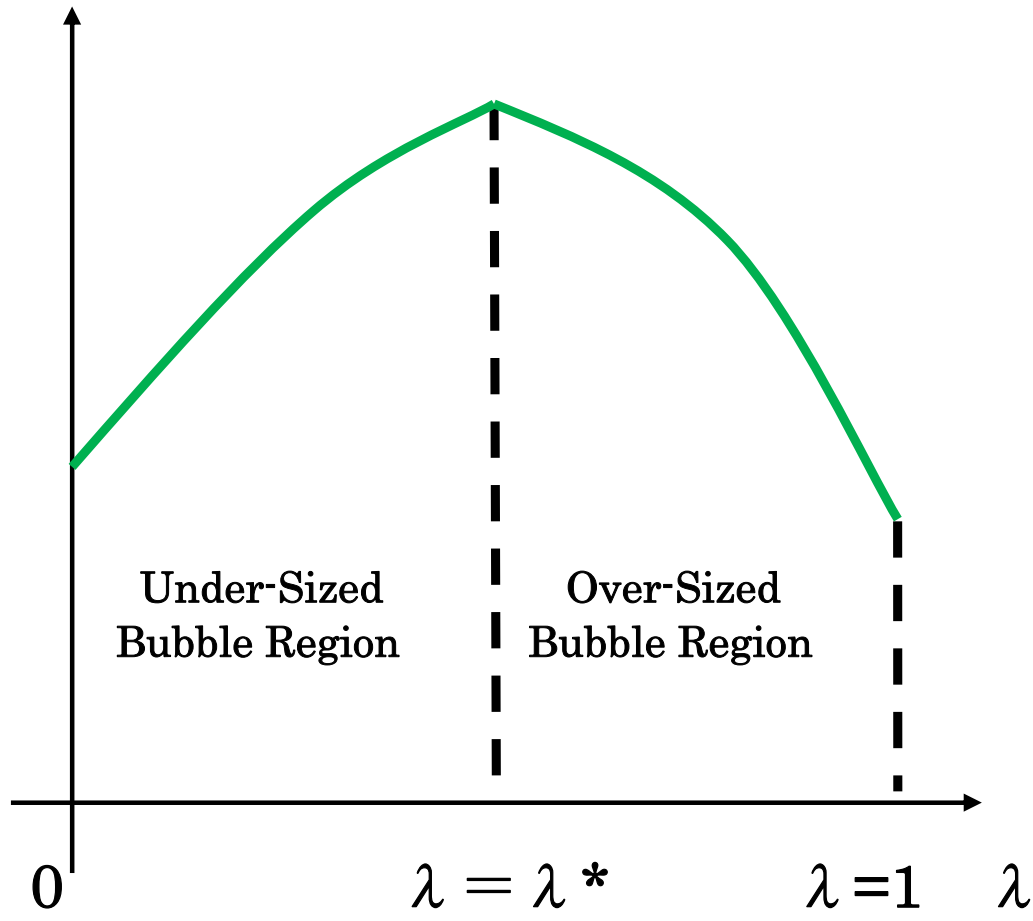


Figure 3
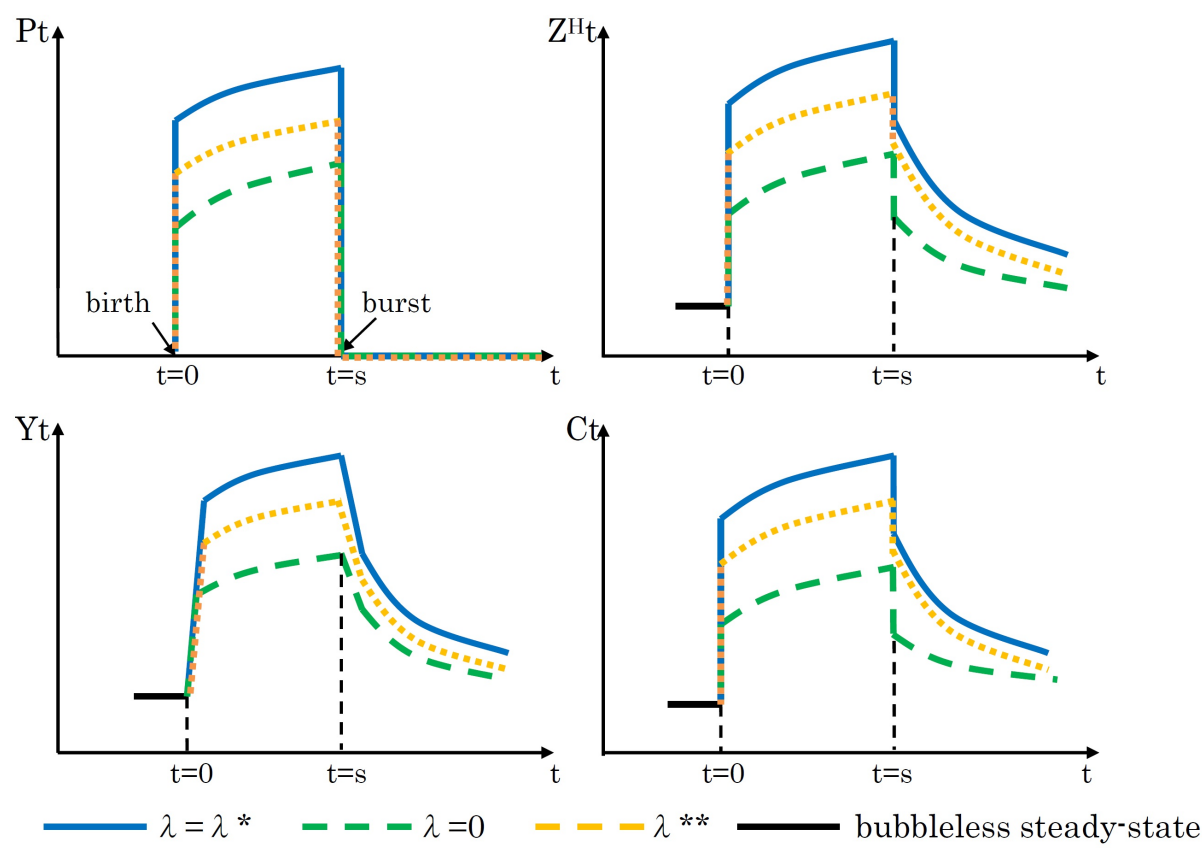

Figure 4
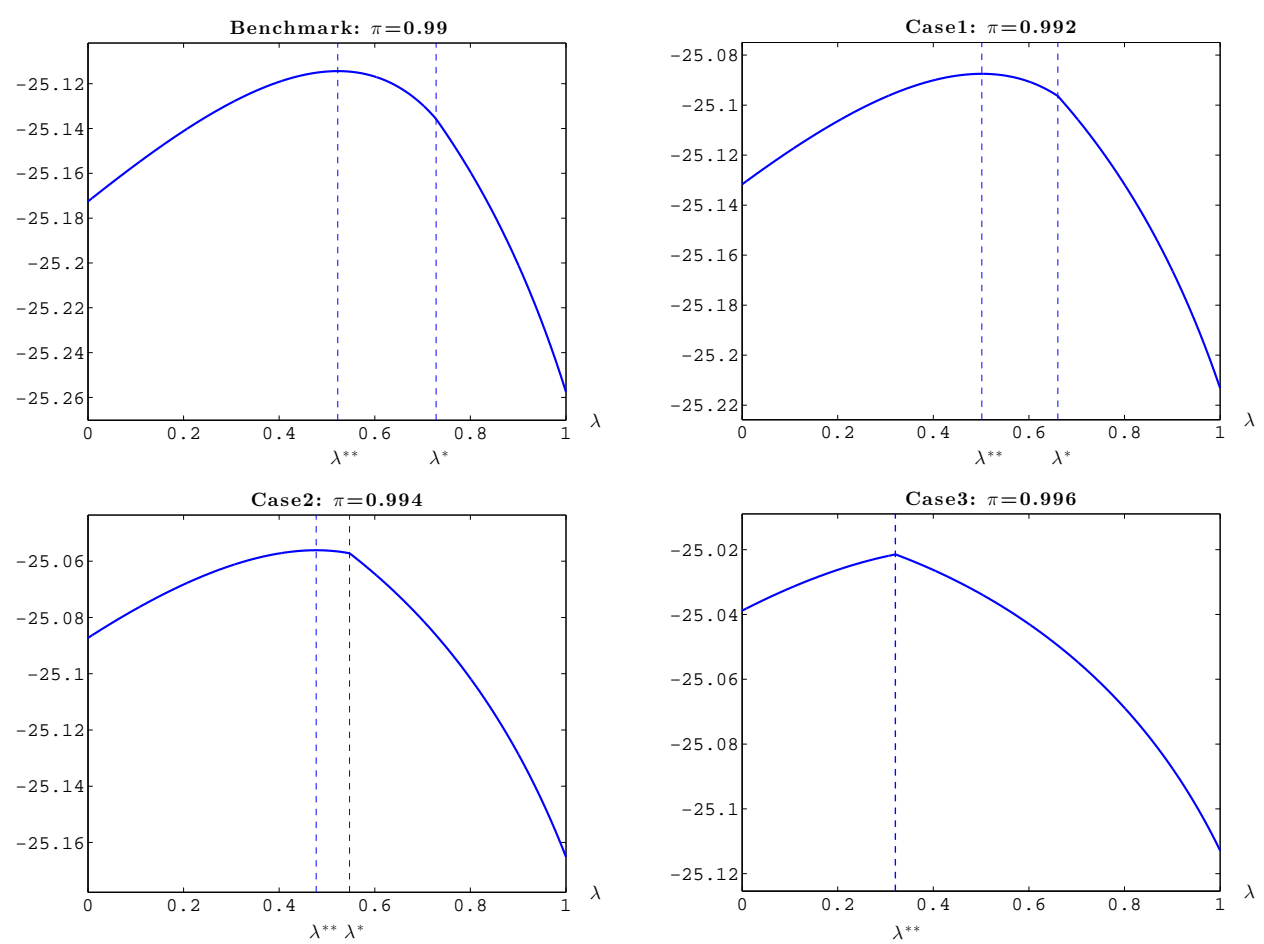
Figure 5

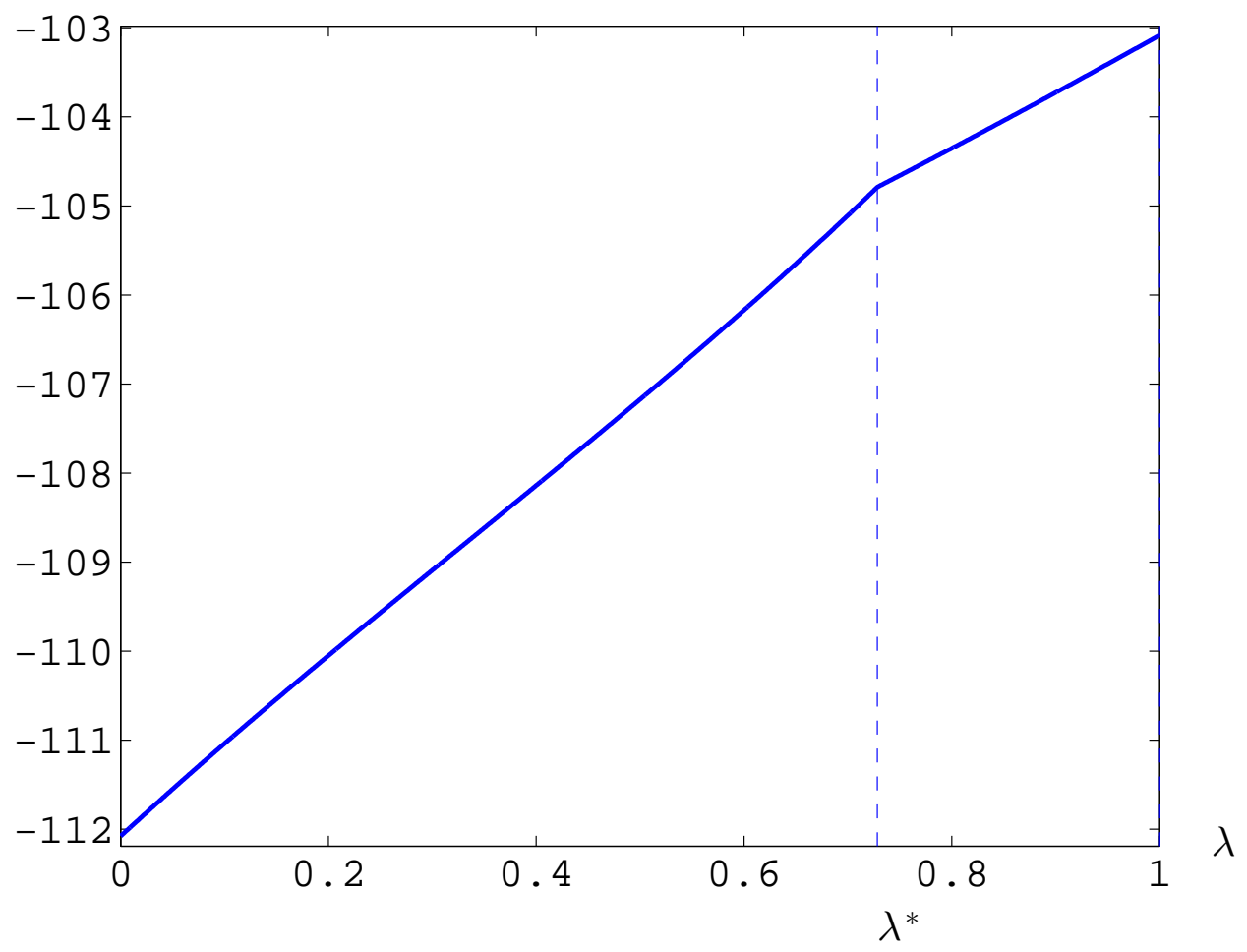

